\title{
Unravelling the Puzzle of Anthranoid Metabolism in Living Plant Cells Using Spectral Imaging Coupled to Mass Spectrometry
}

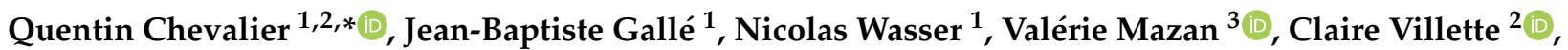 \\ Jérôme Mutterer ${ }^{2}$, Maria Mercedes Elustondo ${ }^{4}$, Nicolas Girard ${ }^{1}\left(\mathbb{D}\right.$, Mourad Elhabiri ${ }^{3}$, Hubert Schaller ${ }^{2}($, \\ Andréa Hemmerlin ${ }^{2}$ and Catherine Vonthron-Sénécheau ${ }^{1}$
}

Citation: Chevalier, Q.; Gallé, J.-B.; Wasser, N.; Mazan, V.; Villette, C.; Mutterer, J.; Elustondo, M.M.; Girard, N.; Elhabiri, M.; Schaller, H.; et al. Unravelling the Puzzle of Anthranoid Metabolism in Living Plant Cells Using Spectral Imaging Coupled to Mass Spectrometry. Metabolites 2021, 11, 571. https://doi.org/10.3390/ metabo11090571

Academic Editor:

Hirokazu Kawagishi

Received: 5 August 2021

Accepted: 23 August 2021

Published: 25 August 2021

Publisher's Note: MDPI stays neutral with regard to jurisdictional claims in published maps and institutional affiliations.

Copyright: (C) 2021 by the authors Licensee MDPI, Basel, Switzerland. This article is an open access article distributed under the terms and conditions of the Creative Commons Attribution (CC BY) license (https:// creativecommons.org/licenses/by/ $4.0 /)$.
1 Centre National de la Recherche Scientifique, Laboratoire d'Innovation Thérapeutique, Université de Strasbourg, CEDEX, F-67401 Illkirch, France; jb.galle@gmail.com (J.-B.G.); n.c.wasser@gmail.com (N.W.); nicolas.girard@unistra.fr (N.G.); vonthron@unistra.fr (C.V.-S.)

2 Institut de Biologie Moléculaire des Plantes, Centre National de la Recherche Scientifique, Université de Strasbourg, CEDEX, F-67084 Strasbourg, France; claire.villette@ibmp-cnrs.unistra.fr (C.V.); jerome.mutterer@ibmp-cnrs.unistra.fr (J.M.); hubert.schaller@ibmp-cnrs.unistra.fr (H.S.); andrea.hemmerlin@ibmp-cnrs.unistra.fr (A.H.)

3 Centre National de la Recherche Scientifique, Laboratoire d'Innovation Moléculaire et Applications, Université de Strasbourg-Université de Haute Alsace, CEDEX, F-67087 Strasbourg, France; mazan@unistra.fr (V.M.); elhabiri@unistra.fr (M.E.)

4 SUPINFO École des Experts des Métiers de 1'Informatique, CEDEX, F-67004 Strasbourg, France; mmelustondo@gmail.com

* Correspondence: qchevalier67@gmail.com; Tel.: +33-367155265

\begin{abstract}
Vismione $\mathrm{H}(\mathrm{VH})$ is a fluorescent prenylated anthranoid produced by plants from the Hypericaceae family, with antiprotozoal activities against malaria and leishmaniosis. Little is known about its biosynthesis and metabolism in plants or its mode of action against parasites. When $\mathrm{VH}$ is isolated from Psorospermum glaberrimum, it is rapidly converted into madagascine anthrone and anthraquinone, which are characterized by markedly different fluorescent properties. To locate the fluorescence of $\mathrm{VH}$ in living plant cells and discriminate it from that of the other metabolites, an original strategy combining spectral imaging (SImaging), confocal microscopy, and non-targeted metabolomics using mass spectrometry, was developed. Besides VH, structurally related molecules including madagascine (Mad), emodin (Emo), quinizarin (Qui), as well as lapachol (Lap) and fraxetin (Fra) were analyzed. This strategy readily allowed a spatiotemporal characterization and discrimination of spectral fingerprints from anthranoid-derived metabolites and related complexes with cations and proteins. In addition, our study validates the ability of plant cells to metabolize $\mathrm{VH}$ into madagascine anthrone, anthraquinones and unexpected metabolites. These results pave the way for new hypotheses on anthranoid metabolism in plants.
\end{abstract}

Keywords: anthranoids; antimalarial drugs; metabolism; spectral imaging; mass spectrometry

\section{Introduction}

The plant kingdom is a source of $\sim 200.000$ identified specialized metabolites of which, $\sim 10.000$ are phenolic compounds also called polyphenols. Many of these metabolites are used as ingredients in the pharmaceutical, cosmetics, and agri-food industries on account of their diverse bioactive properties [1]. Anthranoids form a large class of polyphenols including anthraquinones, anthrones, and bianthrones; these are characterized by anthracene-based structures with various degree of oxidations and are conjugated with sugars and/or prenyl groups [2]. The biological action of several anthraquinones widely considered in the literature has demonstrated the need for the presence of specific functions. For instance, in the case of emodin (Emo), hydroxyl groups at position 1 and 8 of the 
anthracene ring (Figure $1 \mathrm{~A}$ ) are mandatory for its purgative properties [3,4]. Vismione $\mathrm{H}$ $(\mathrm{VH})($ Figure $1 \mathrm{~A})$ is a prenylated anthranoid, generating significant interest due to promising antimalarial and antileishmanial activities [5,6]. Chemical inventories of botanical resources, structural elucidation, and biological activities of natural products like $\mathrm{VH}$ allowed a compilation of comprehensive repositories for potential drugs. Still, fundamental questions about their biosynthesis in planta their molecular targets for biological activities, and their metabolization in cells into potentially active derivatives remain unsolved. In plants, anthranoids are biosynthesized through two distinct pathways: the polyketide pathway occurs in the Rhamnaceae, Fabaceae, Aloeaceae, and Polygonaceae families, while the shikimate/o-succinylbenzoic acid pathway is found in Rubiaceae [7]. Recently, genome mining identified new candidates for anthraquinones biosynthesis enzymes in Senna tora plants [8]. Anthranoid metabolism has also been reported in mushrooms belonging to the Cortinarius genus and in Aspergillus nidulans $[9,10]$. These data suggest that O-methylation, oxidation, hydroxylation, dimerization, and glycosylation may be enzyme-catalyzed, while other modifications could result from chemical reactions such as tautomerization, photoisomerization, and photochemical hydroxylation [11-13]. Under oxidative conditions such as in DMSO, the VH isolated from Psorospermum glaberrimum spontaneously degrades into the anthrone form, which is then oxidized into its madagascine (Mad) anthraquinone form or alternatively dimerized into bianthrones [6].

\section{A Natural fluorescent bioactive compounds}

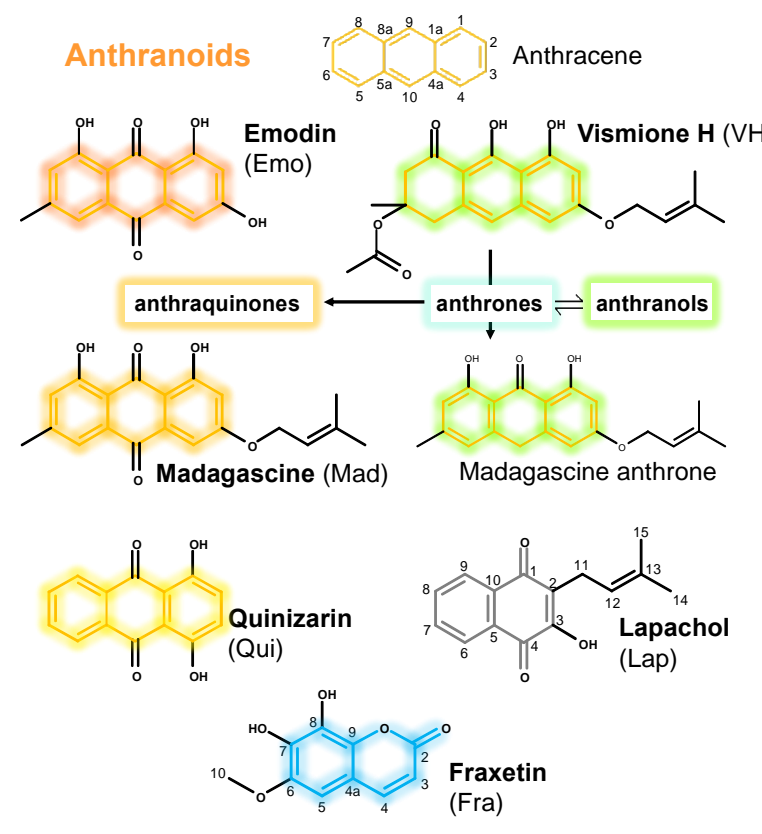

\section{B Fluorescence study workflow}

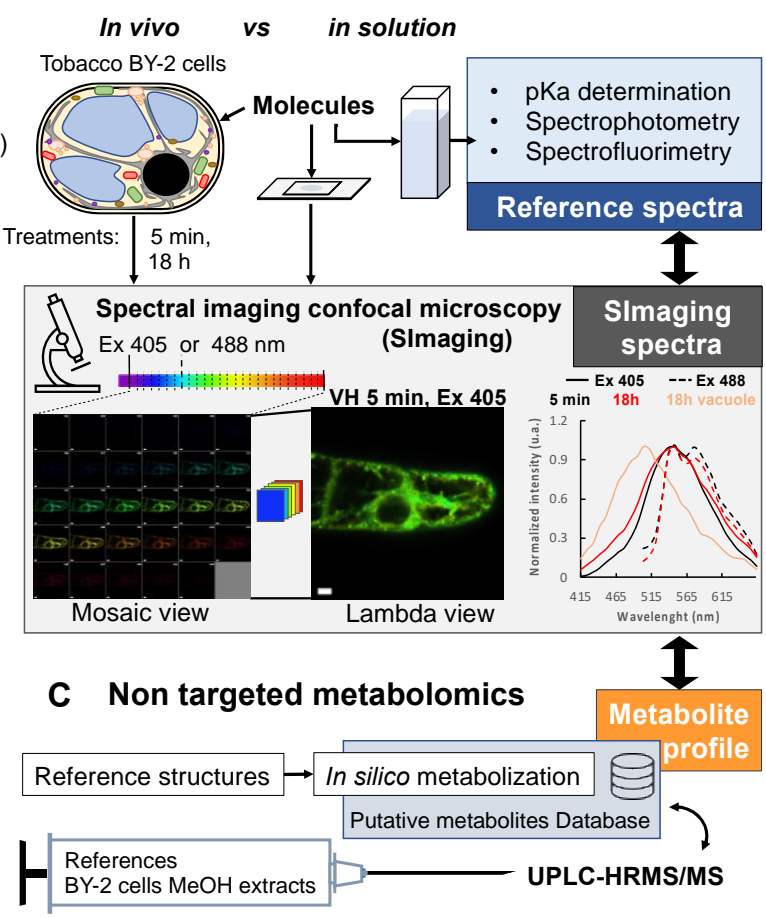

Figure 1. Overview of natural fluorescent bioactive anthranoids and the original approach used to study their localization and biotransformation in living cells. (A) Chemical structures of anthranoids characterized by the anthracene skeleton (orange skeleton) as compared to other phenolic compounds such as the naphthoquinone lapachol (Lap, grey skeleton) and the coumarin fraxetin (Fra, blue skeleton). In dimethylsulfoxide (DMSO), vismione $\mathrm{H}(\mathrm{VH})$ degrades quickly into anthrones (weak turquoise fluorescence) being in equilibrium with anthranol tautomers (strong green yellowish) and oxidized into anthraquinones such as emodin (Emo), madagascine (Mad) or quinizarin (Qui) (yellow to red fluorescence). (B,C) Spectral imaging and non-targeted metabolomic workflow to characterize biotransformation of fluorescent anthranoids in tobacco BY-2 cells. (B) Fluorescence of selected anthranoids is evaluated in solution, then these anthranoids $(25$ or $50 \mu \mathrm{M})$ are used to feed cells for confocal spectral imaging microscopy observations at $5 \mathrm{~min}$ and $18 \mathrm{~h}$ after feeding. (C) Non-targeted metabolomics workflow implementing high-resolution mass spectrometry analysis of methanolic extracts from cells characterized in (B). 
Within the entire UV-Vis. spectrum, more than 300 naturally occurring fluorescent compounds have been reported with quantum yields ranging from $0.01 \%$ to $100 \%$ in vitro [14] In fact, the number and position of substituents, especially hydroxyl groups impact the physico-chemical (i.e., protonation) and fluorescence properties of anthranoids [14].

The acetyl vismione $D$ emits green fluorescence $\left(\lambda_{\mathrm{Em}}=534 \mathrm{~nm}\right)$ in methanol with a low quantum yield of about $2 \%$ [6], whereas anthrones/anthranols emit light at a blue wavelength $\left(\lambda_{\mathrm{Em}}=458 \mathrm{~nm}\right)$ in alcohols and a strong yellow-green fluorescence in water $\left(\lambda_{\mathrm{Em}}=539 \mathrm{~nm}\right)$ [15]. In regards to anthraquinones such as quinizarin (Qui) (Figure 1A) or hypericin, both fluoresce in the orange to far red window $(570-675 \mathrm{~nm})$ with quantum yields up to 30\% [14-17]. Overall, the specific fluorescence properties of $\mathrm{VH}$, anthrone, and anthraquinone forms have never been exploited in integrative biochemical approaches, especially to elucidate their biosynthesis, metabolism, cell compartmentation, and bioactivity in living cells.

Spectral imaging (SImaging) enables the simultaneous detection of emitted fluorescence in multiple independent channels with a resolution of $<10 \mathrm{~nm} /$ channel (Figure 1B). Auto-fluorescent phenolic compounds such as simple phenols, vanillin, and mangiferin were indeed observed by SImaging [18,19]. Here, SImaging combined with high-resolution mass spectrometry was implemented to track VH and related anthranoids (Mad, Emo, Qui) and were compared to a prenylated naphthoquinone lapachol (Lap) in tobacco BY-2 cells (Figure 1A,B). Tobacco cells were chosen as a model because they are inexpensive, safe, easy to handle, and free of auto-fluorescent compounds under standard conditions [20]. Fraxetin (Fra) was used as a positive control because its fluorescence and metabolism are reported in Arabidopsis and tobacco BY-2 cells [21,22]. To faithfully characterize the molecules on the basis of their fluorescence observed by SImaging, we performed a spectrofluorometric analysis of the pure compounds in solution as a reference (Figure 1B). This comparison enabled the identification of natural product fluorescence signals within different cell compartments at a single time point. Combined with non-targeted metabolomics (UPLC-HRMS/MS) of treated tobacco cells, providing unique and accurate annotations of fluorescent metabolites (Figure 1C), this elegant photobiochemistry approach offers a fresh view on the fate of the antimalarial agent vismione $\mathrm{H}$ in living plant cells.

\section{Results}

\subsection{PH Influences the Spectral Properties of Compounds in Solution}

$\mathrm{pH}$ values and composition in salts differ in plant sub-cellular compartments, hinging on cell type, the developmental stage, and the environment [23,24]. As the intracellular $\mathrm{pH}$ in plant cells ranges from 5 in the primary vacuole, up to 8 in the mitochondrial matrix and peroxisomes $[25,26]$, we investigated in detail the photophysical properties of anthranoids and coumarins, whose fluorescence is under physiochemical control. It is noteworthy that all studied compounds showed at least two main absorption bands, one with high absorptivity at wavelengths below $300-320 \mathrm{~nm}$ and another less intense band at much lower energies (from 350-600 nm, Figure S1 and Table S1). In all of the examined systems, a significant bathochromic shift of the absorption lying at lower energies was observed upon increasing the $\mathrm{pH}$. In contrast, a hypochromic shift of the main absorption band and the emergence of a weak absorption band, centered at about $500 \mathrm{~nm}$ under basic conditions, was observed for $\mathrm{VH}$ (Figure S1A-C). As reported for other polyphenols [27,28], these results showcase the impact of the moderate acidity and the associated hydroxyl deprotonation of the investigated polyphenols on their respective absorption spectral characteristics. In addition, the second absorption centered at $350-600 \mathrm{~nm}$ is appropriate to SImaging methodology settings and to those of most confocal microscopes.

Among the six compounds studied, except for Lap (Figure S2F), all compounds emitted fluorescence when excited between $350-520 \mathrm{~nm}$ (Figure 2). In an organic solvent such as ethyl acetate, VH did not emit fluorescence as compared to anthraquinones (Figure S2A-D), whereas Fra could only be excited by $\lambda<330 \mathrm{~nm}$ (Figure S2E). Still, in saline ethanolic solution at $\mathrm{pH} 2$ (i.e., fully protonated and neutral species), $\mathrm{VH}$ and anthraquinones were 
found to be fluorescent and their absolute quantum yields $\Phi_{\mathrm{F}}$ ranged from 0.7 to $15.1 \%$ (Table 1, Figure 2A-E). Surprisingly, although Mad only differs from the Emo by the prenylated C3-OH group (Figure $1 \mathrm{~A}$ ), its absolute quantum yield $\Phi_{\mathrm{F}}=4.8 \%$ was found to be 6 times higher than that of Emo $\Phi_{\mathrm{F}}=0.7 \%$. The 1,4-dihydroxyanthraquinone Qui was found to be the most fluorescent anthraquinone with a $\Phi_{\mathrm{F}}=15.1 \%$. These results indicate that the number and position of hydroxyl groups as well as other types of substitutions (e.g., prenyl group on position 3 for Mad) on anthraquinones contribute to the brightness of their fluorescence emission. In addition, anthraquinones show a drastic loss of their fluorescence emission intensity (Figure S2B-D) when the $\mathrm{pH}$ value is higher than the $\mathrm{pK}_{\mathrm{a} 1}$ (i.e., monodeprotonated species, Table S1), and vice versa for Fra or VH (catechol for Fra or naphthalene-1,8-diol for VH, Figure S2A-E). Nonetheless, a subsequent increase of $\mathrm{pH}$ to 12 and higher lead to the progressive loss of Fra and VH fluorescence (Figure S2A-E). It can be speculated that the former likely promoted $\mathrm{VH}$ and Fra degradation into other compounds by lactone ring opening or anthraquinone formation from $\mathrm{VH}$ as previously described in DMSO $[6,29,30]$. Interestingly, the $\lambda_{\mathrm{Em}}$ values measured for $\mathrm{VH}$ in $\mathrm{NH}_{4} \mathrm{HCO}_{3}$ and $\mathrm{Na}_{2} \mathrm{~B}_{4} \mathrm{O}_{7}$ buffers at $\mathrm{pH} 10$ were found to be bathochromically shifted from 481 to 533 $\mathrm{nm}\left(\mathrm{LNH}_{4}{ }^{+} \Phi_{\mathrm{F}}=24.0 \%\right)$ and $532 \mathrm{~nm}\left(\mathrm{LB} \Phi_{\mathrm{F}}=31 \%\right)$, respectively (Table 1, Figure $2 \mathrm{~B}$ and Figure S3A).
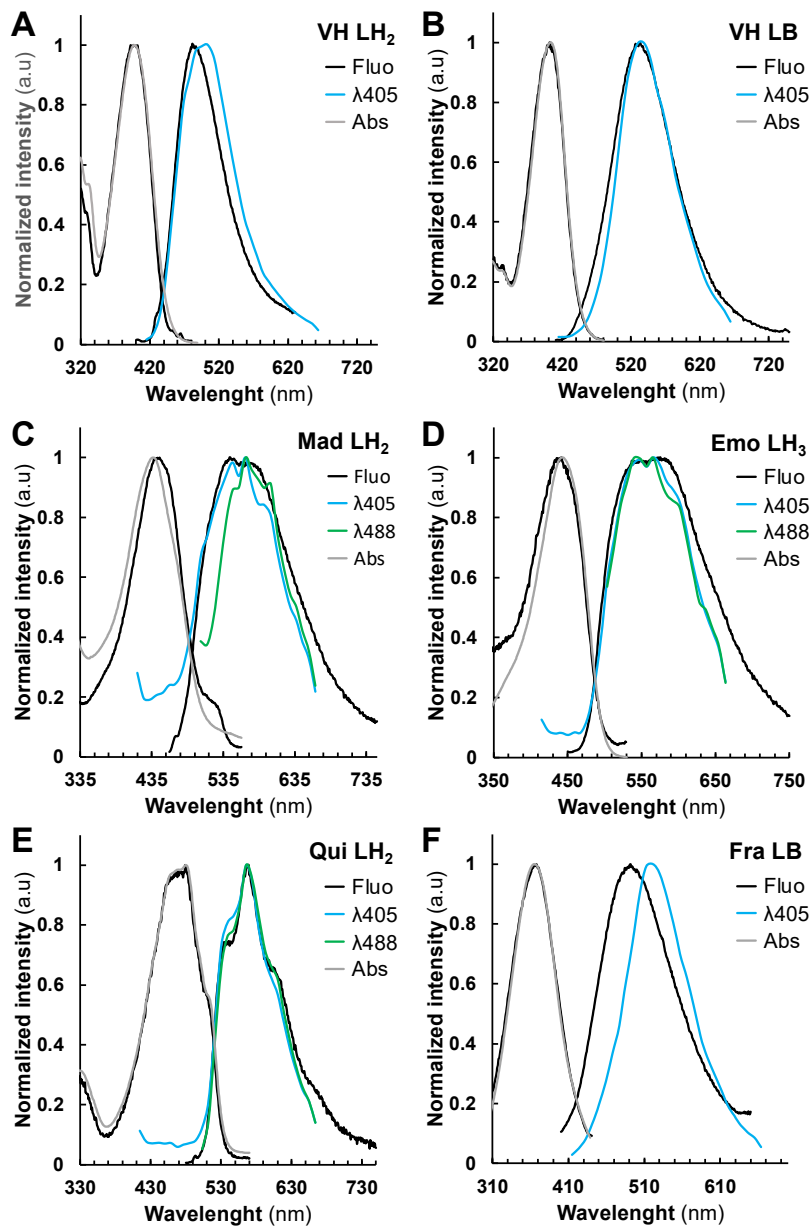

Figure 2. Normalized fluorescence excitation/emission and absorption spectra of studied compounds. (A) vismione $\mathrm{H} \mathrm{VH}$ (neutral $\mathrm{LH}_{2}$ species) and (B) (boron complex LB species), (C) quinizarin Qui (neutral $\mathrm{LH}_{2}$ species), (D) emodin Emo (neutral $\mathrm{LH}_{3}$ species), (E) madagascine Mad (neutral $\mathrm{LH}_{2}$ species), (F) fraxetin Fra (boron complex LB species) in saline ethanolic solutions. Excitation and emission spectra obtained from the spectrofluorimetric analysis (black), absorption spectra obtained from the UV-Vis. analysis (grey), and SImaging at $\lambda_{405}$ (blue) and/or $\lambda_{488}$ (green) settings. 
Table 1. Main photophysical characteristics of fluorescent species.

\begin{tabular}{|c|c|c|c|c|c|c|c|}
\hline Compounds Name & $\begin{array}{c}{[\mathrm{C}]} \\
(\mu \mathrm{M})\end{array}$ & $\begin{array}{l}\lambda \text { abs } \\
(\mathrm{nm})\end{array}$ & $\left(104 \mathrm{M}^{-1} \mathrm{~cm}^{-1}\right)$ & $\begin{array}{l}\lambda \mathrm{Ex} \\
(\mathrm{nm})\end{array}$ & $\begin{array}{l}\lambda \mathrm{Em} \\
(\mathrm{nm})\end{array}$ & $\begin{array}{l}\Phi F \\
(\%)\end{array}$ & $\begin{array}{l}\text { SI } \lambda E m \\
(\mathrm{~nm})\end{array}$ \\
\hline Vismione $\mathrm{H}\left(\mathrm{LH}_{2}\right)^{\mathrm{a}}$ & \multirow{6}{*}{2.6} & 398 & 1.1 & 396 & 481 & 3.9 & 503 \\
\hline Vismione H (LB) ${ }^{b}$ & & 403 & 1.40 & 402 & 532 & 31.0 & 530 \\
\hline Vismione $\mathrm{H}\left(\mathrm{LNH}_{4}^{+}\right)^{\mathrm{c}}$ & & 403 & 1.93 & 403 & 533 & 24.0 & 530 \\
\hline Vismione $\mathrm{H}-\mathrm{Ca}(\mathrm{LCa})^{\mathrm{d}}$ & & 404 & 1.36 & 404 & 549 & 19.8 & 548 \\
\hline Vismione $\mathrm{H}-\mathrm{Mg}(\mathrm{LMg})^{\mathrm{e}}$ & & 407 & 1.40 & 404 & 550 & 18.6 & 548 \\
\hline Vismione H-BSA (LBSA) ${ }^{f}$ & & 404 & 1.21 & 404 & 517 & 23.5 & 530 \\
\hline Emodin $\left(\mathrm{LH}_{3}\right)^{\mathrm{a}}$ & 5.55 & 443 & 1.68 & 442 & 575 & 0.7 & 565 \\
\hline Madagascine $\left(\mathrm{LH}_{2}\right)^{\mathrm{a}}$ & 2.96 & 437 & 0.64 & 446 & 544 & 4.8 & 565 \\
\hline Quinizarin $\left(\mathrm{LH}_{2}\right)^{\mathrm{a}}$ & 4.16 & 480 & 0.38 & 479 & 569 & 15.1 & 565 \\
\hline Fraxetin (LB) ${ }^{b}$ & \multirow{3}{*}{4.8} & 366 & 1.05 & 367 & 492 & 1.1 & 521 \\
\hline Fraxetin $\left(\mathrm{LNH}_{4}^{+}\right)^{\mathrm{c}}$ & & 399 & 0.87 & 382 & 481 & 0.8 & 521 \\
\hline Fraxetin-BSA (LBSA) ${ }^{f}$ & & 410 & 2.04 & 410 & 490 & 8.4 & 503 \\
\hline
\end{tabular}

The absorption $\left(\lambda_{\mathrm{abs}}\right)$, excitation $\left(\lambda_{\mathrm{Ex}}\right)$ and emission $\left(\lambda_{\mathrm{Em}}\right)$ maxima obtained by spectrofluorimetry and SImaging (SI $\left.\lambda_{\mathrm{Em}}\right)$, the molar extinction coefficient $(\varepsilon)$ and quantum yields determined for the pure compounds at different concentration ([C]) in model solutions. $\mathrm{EtOH} / \mathrm{H}_{2} \mathrm{O} 1: 1 v / v, 0.1 \mathrm{M} \mathrm{NaCl}$ with a $0.01 \mathrm{M} \mathrm{HCl}$ at pH 2, ${ }^{\mathrm{b}} 0.01 \mathrm{M} \mathrm{Na}_{2} \mathrm{~B}_{4} \mathrm{O}_{7}$ at $\mathrm{pH} 10,{ }^{\mathrm{c}} 0.01 \mathrm{M} \mathrm{NH}_{4} \mathrm{HCO}_{3}$ at pH 10, ${ }^{\mathrm{d}} 15 \mathrm{mM} \mathrm{CaCl}_{2}$, e $15 \mathrm{mM} \mathrm{MgCl}_{2}$, or ${ }^{\mathrm{f}} \mathrm{H}_{2} \mathrm{O}$ containing $300 \mu \mathrm{M}$ BSA. The errors on $\varepsilon$ and $\Phi_{\mathrm{F}}$ are estimated to $10 \%$, the errors on $\lambda$ are estimated to $\pm 1 \mathrm{~nm}$.

In $\mathrm{Na}_{2} \mathrm{~B}_{4} \mathrm{O}_{7}$ buffer, $\mathrm{VH}$ is strongly emitting as reported for anthranol in the Schouteten reaction [15]. Similarly, Fra $\lambda_{\mathrm{Em}}$ was $492 \mathrm{~nm}\left(\mathrm{LB} \Phi_{\mathrm{F}}=1.1 \%\right)$ and $481 \mathrm{~nm}\left(\mathrm{LNH}_{4}{ }^{+} \Phi_{\mathrm{F}}=0.8 \%\right)$ in $\mathrm{NH}_{4} \mathrm{HCO}_{3}$ (Table 1, Figure $2 \mathrm{~F}$ and Figure S3B). These results indicate that in cellular environments with acidity ranging from 4 to 7.8 , all compounds except Lap and Fra would emit fluorescence if excited at $\lambda_{\mathrm{Ex}}$ ranging from 392 to $480 \mathrm{~nm}$.

As far as Fra and VH are concerned, the distinct photophysical properties of the LB and $\mathrm{LNH}_{4}{ }^{+}$characterized species support the fact that these two compounds are likely able to chelate boron as already reported for $\mathrm{Mg}^{2+}$ or $\mathrm{Fe}^{2+}$ with Fra and anthraquinones [21,31], but also ammonium. In this context, we carefully investigated the influence of metals $\left(\mathrm{Ca}^{2+}\right.$ and $\left.\mathrm{Mg}^{2+}\right)$ and the BSA as model protein for chelation experiments, on the $\mathrm{VH}$ emission properties.

\subsection{Metal and Protein Chelations Influence VH Fluorescence Properties}

$\mathrm{Ca}^{2+}$ and $\mathrm{Mg}^{2+}$ were selected for complexation studies not only because of their abundance in plant cells, but also for their key roles in cell structure and physiology such as signaling pathways or the water splitting complex of photosystems [32-34]. BSA was selected as a protein model as it has already been used for protein chelation assays with other fluorescent compounds [35]. Thus, we evaluated the absorption $(26 \mu \mathrm{M} \mathrm{VH})$ and fluorescence $(2.6 \mu \mathrm{M} \mathrm{VH})$ properties of $\mathrm{VH}$ in EtOH/water $1: 1 v / v$ containing $0.1 \mathrm{M}$ of $\mathrm{NaCl}$ in the presence of $\mathrm{Mg}^{2+}$ or $\mathrm{Ca}^{2+}$. As BSA precipitated under these experimental conditions, the protein complexation studies were performed only in water. Accordingly, VH chelates both $\mathrm{Mg}^{2+}$ and $\mathrm{Ca}^{2+}$ with a comparable affinity (Figure 3, Figures S4 and S5). From the UV-Vis. absorption titrations, $\log K_{\mathrm{VHM}}$ values of $2.31 \pm 0.07$ and $2.24 \pm 0.06$ respectively, were calculated and indicated that substantial amounts of $\mathrm{VH}-\mathrm{Ca}$ or $\mathrm{VH}-\mathrm{Mg}$ complexes can be formed within the cells. In both cases, about $70 \%$ of $\mathrm{VH}(26 \mu \mathrm{M})$ complexation was achieved with $6 \mathrm{mM}$ of $\mathrm{CaCl}_{2}$ or $\mathrm{MgCl}_{2}$. Although $\mathrm{VH}$ displays similar binding strength with these metal ions, the absorption data pointed out different binding modes (Figures $\mathrm{S} 4$ and S5). 

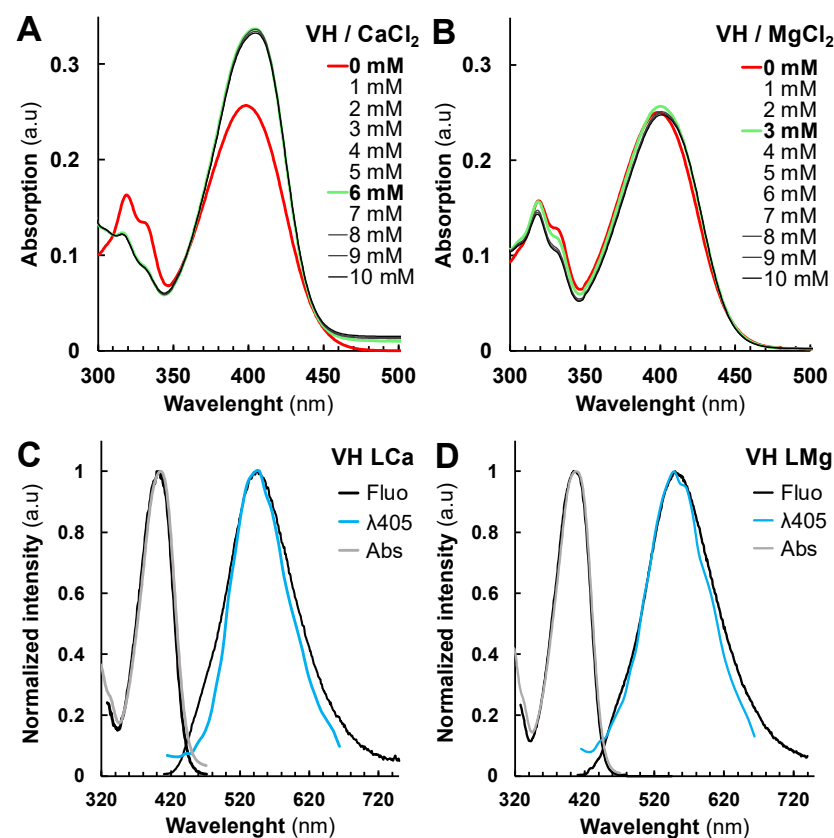

Figure 3. Vismione H VH photophysical properties are influenced by metal cations complexation. (A,B) Absorption spectra of metal complexes formed by VH with different amount of Ca (II) (A) and (B) $\mathrm{Mg}$ (II) spectra with no complex formed (bold red) and with the highest changes in the absorption spectrum (bold green). Normalized fluorescence (black), absorption (grey) and SImaging spectra of $\mathrm{VH}-\mathrm{Ca}(\mathbf{C})$ and (D) $\mathrm{VH}-\mathrm{Mg}$ complexes at $\lambda_{405}$ settings.

Marked spectral differences observed in the case of $\mathrm{Ca}^{2+}$ as compared to $\mathrm{Mg}^{2+}$ assert divergent coordination preferences. As reported, carboxylates preferentially act as bidentate binders with $\mathrm{Ca}^{2+}$ and as monodentate ligands with $\mathrm{Mg}^{2+}$ in proteins [36]. This property could explain our absorption data with $\mathrm{VH}$ acting as bidentate ligand with $\mathrm{Ca}^{2+}$ ( $\beta$-hydroxy-ketone binding unit leading, Figure S1A,B), while preferentially coordinating $\mathrm{Mg}^{2+}$ with monodentate binding unit mode (phenolate unit).

Fluorescence analysis of $\mathrm{VH}-\mathrm{Ca}$ and $\mathrm{VH}-\mathrm{Mg}$ complexes in solution confirmed the impact of chelation on photophysical properties. The maximum of emission $\lambda_{\mathrm{Em}}$ for $\mathrm{VH}-\mathrm{Ca}$ and VH-Mg (549 $\pm 1 \mathrm{~nm})$ complexes was found to be higher than that of the VH LB or $\mathrm{LNH}_{4}{ }^{+}$species (532 $\pm 1 \mathrm{~nm}$ ) (Table 1). Nonetheless, the $\Phi_{\mathrm{F}}$ of VH-Ca $(19.8 \%)$ and VH-Mg $(18.6 \%)$ complexes were substantially lower than that of VH LB (31\%) species, but still much higher than the neutral species $\left(3.7 \%\right.$ for $\left.\mathrm{VH} \mathrm{LH}_{2}\right)$. We then evaluated the binding strength of $\mathrm{VH}$ and Fra with the BSA protein model, both by absorption and emission means (Figure $\mathrm{S} 6 \mathrm{~A}, \mathrm{~B}, \mathrm{E}, \mathrm{F})$. VH and Fra were found to strongly interact with BSA, with stability constants $\log K_{\mathrm{VHBSA}}$ and $\log K_{\mathrm{FraBSA}}$ values of $5.3 \pm 0.2$ and $5.7 \pm 0.3$ (Figure S7), respectively. This suggests that $\mathrm{VH}$ and Fra would interact mainly with proteins rather than with divalent metal ions in cellula. VH chelates BSA protein with a weak alteration of the absorption properties as seen previously with $\mathrm{Mg}^{2+}$ (Figure 3B and Figure S7A,B), while the absorption properties of Fra were significantly altered (Figure S7E,F). The $\lambda_{\mathrm{Em}}$ of VH LBSA fluorescence spectrum corresponded to $517 \mathrm{~nm}$ with $\Phi_{\mathrm{F}}=23.5 \%$, close to that of VH $\mathrm{LNH}_{4}{ }^{+}$species (Table 1, Figure S3C), while Fra-BSA result was 10 times higher than that of Fra LNH4+ species (Table 1, Figures S3D and S6F,G). It can be proposed that electrostatic interactions with ammonium residues such as those found in lysine or arginine, allow complexation of VH with proteins as compared to Fra which seems to interact with other amino acid residues. In contrast, Emo and Qui emissions were almost unaffected in the presence of BSA (Figure S6C,D,G,H), as reported for complexes with DNA [17]. Overall, although neutral $\mathrm{VH}$ and $\mathrm{Fra} \mathrm{LH}_{2}$ with low $\Phi_{\mathrm{F}}$ seemingly predominate at intracellular $\mathrm{pH}$, our results suggest that interactions with endogenous metal ions or proteins might improve/modulate their fluorescence properties in cellula. 


\subsection{Fluorescent Anthranoids Metabolization and Transport in Cellula by Spectral Imaging}

To characterize the fluorescence in cellula, we compared the reference emission spectra obtained from our spectrofluorimetric analysis to those measured by SImaging in solution and in living BY-2 cells. SImaging methods were used to discriminate mixed fluorescent signals from the studied compounds in solution and in BY-2 cells with a special focus on vismione $\mathrm{H}$ (blue to green-yellowish emission) and related anthraquinones (yellow to red emission) (Figure 1A). With respect to the photophysical data, two different settings were selected for the excitation and detection of fluorescence using. SImaging: $\lambda_{\mathrm{Ex}}=405 \mathrm{~nm}$ $\left(\lambda_{405}\right)$ with emission spectra ranges from 415 to $664 \mathrm{~nm}$, and $\lambda_{\mathrm{Ex}}=488 \mathrm{~nm}\left(\lambda_{488}\right)$ with emission spectra ranges from 495 to $664 \mathrm{~nm}$. The fluorescence data obtained by SImaging on pure compounds in solution at $\lambda_{405}$ and $\lambda_{488}$ fit well with those obtained by the spectrofluorimetric approach (Figure 2, Figure 3 and Figure S3). However, some variations can be observed such as a decrease in the intensity of the shoulder of the $\mathrm{Emo}^{\mathrm{LH}} \mathrm{H}_{3}$ at $575 \mathrm{~nm}$ or a shift from 484 to $503 \mathrm{~nm}$ for the $\mathrm{VH} \mathrm{LH}_{2}$ or from 492 to $521 \mathrm{~nm}$ for the Fra LB. These discrepancies could be related to differences in resolution, glass support or optical path between SImaging ( $9 \mathrm{~nm}$, glass microscope slide, $1 \mathrm{~mm})$ and spectrofluorimetry $(1 \mathrm{~nm}$, quartz cell, $1 \mathrm{~cm}$ ). In addition, the hydrophobic character of Mad was appreciated by the observation of aggregates at $1 \mathrm{mM}$ Mad in hydro-alcoholic solution at $\mathrm{pH} 2$ (Figure S8). Although the $\Phi_{\mathrm{F}}$ of Mad is higher than that of Emo, its lower solubility results in a lower fluorescence signal, which reduces the quality of spectra recorded at $\lambda_{488}$ or $\lambda_{405}$ for Mad in solution. To note, this solubility problem was also observed in the cell culture medium after treatments, leading to the formation of aggregates still present after $18 \mathrm{~h}$.

In vivo, very low fluorescence was detected in control (Ctr) and Lap-treated cells (Figure 4F, Figures S9 and S10F). We defined these signals as the autofluorescence threshold in tobacco BY-2 cells. For all other compounds, the emergence of fluorescence was clearly observed in treated BY-2 cells $(5 \mathrm{~min})$ being stable after $18 \mathrm{~h}$ treatments with either $25 \mu \mathrm{M}$ (Figure $4 \mathrm{~A}-\mathrm{E}$ ) or $50 \mu \mathrm{M}$ (Figure S10A-E). Overall, excitation at $\lambda_{405}$ resulted in a stronger fluorescence signal than at $\lambda_{488}$, but the opposite effect was observed with Qui- (Figure 4B) and Mad-treated cells (Figure 4D). As evidenced by our spectral analysis, only Fra-treated cells did not display fluorescence at a $\lambda_{488}$ excitation (Figure $4 \mathrm{E}$ ). Except for $\mathrm{VH}$, all spectra recorded at $5 \mathrm{~min}$ after treatment were very similar (same $\lambda_{\mathrm{Em}}$ and shape) and independent of $\lambda_{\mathrm{Ex}}$ (Figure 4B-E and Figure S10). PCA of the normalized average spectra support the idea that the emission spectrum observed at $\lambda_{488}$ in VH-treated cells shares similarities with those measured with Qui and especially Mad, but not with spectra found in Emotreated cells (Figure 5B and Figures S11B-S13B). Besides, the emission maxima observed in $\mathrm{VH}$ and Mad-treated cells (mostly in vesicular bodies) following excitation at $\lambda_{488}$, were centered at $539 \mathrm{~nm}$ and $575 \mathrm{~nm}$. Even though the emission spectra recorded for $\mathrm{VH}$ - and Mad-cells share similarities with that of Qui-treated cells, the maximum of emission for Qui-treated cells was centered at $575 \mathrm{~nm}$. These results strongly suggest that within the first minutes, $\mathrm{VH}$ and Mad lead to similar anthraquinones differing from those produced in both Emo- and Qui-treated cells. Interestingly, the fluorescence emission detected was usually observed first in the cytoplasm (Figure S14), and after $5 \mathrm{~min}$ in additional structures such as Golgi bodies (Figure S15), lipid droplets (Figure S16), and the ER (Figure S17). Specifically for Fra-treated cells excited at $\lambda_{405}$, a fluorescence emission was observed in the nucleus. Therefore, molecules are well absorbed by BY-2 cells and diffuse in different cell compartments following their polarity. The difference of shape and intensity between spectra collected in $\mathrm{VH}$-treated cells suggests that at $\lambda_{405}$ the monodeprotonated or complexed $\mathrm{VH}$ is detected in the cytoplasm and the ER, while at $\lambda_{488}$ anthraquinones are predominantly observed in vesicular bodies such as lipid droplets and some Golgi bodies. After $18 \mathrm{~h}$, at $\lambda_{488}$ or $\lambda_{405}$ slight variations were detected in fluorescence intensities. 

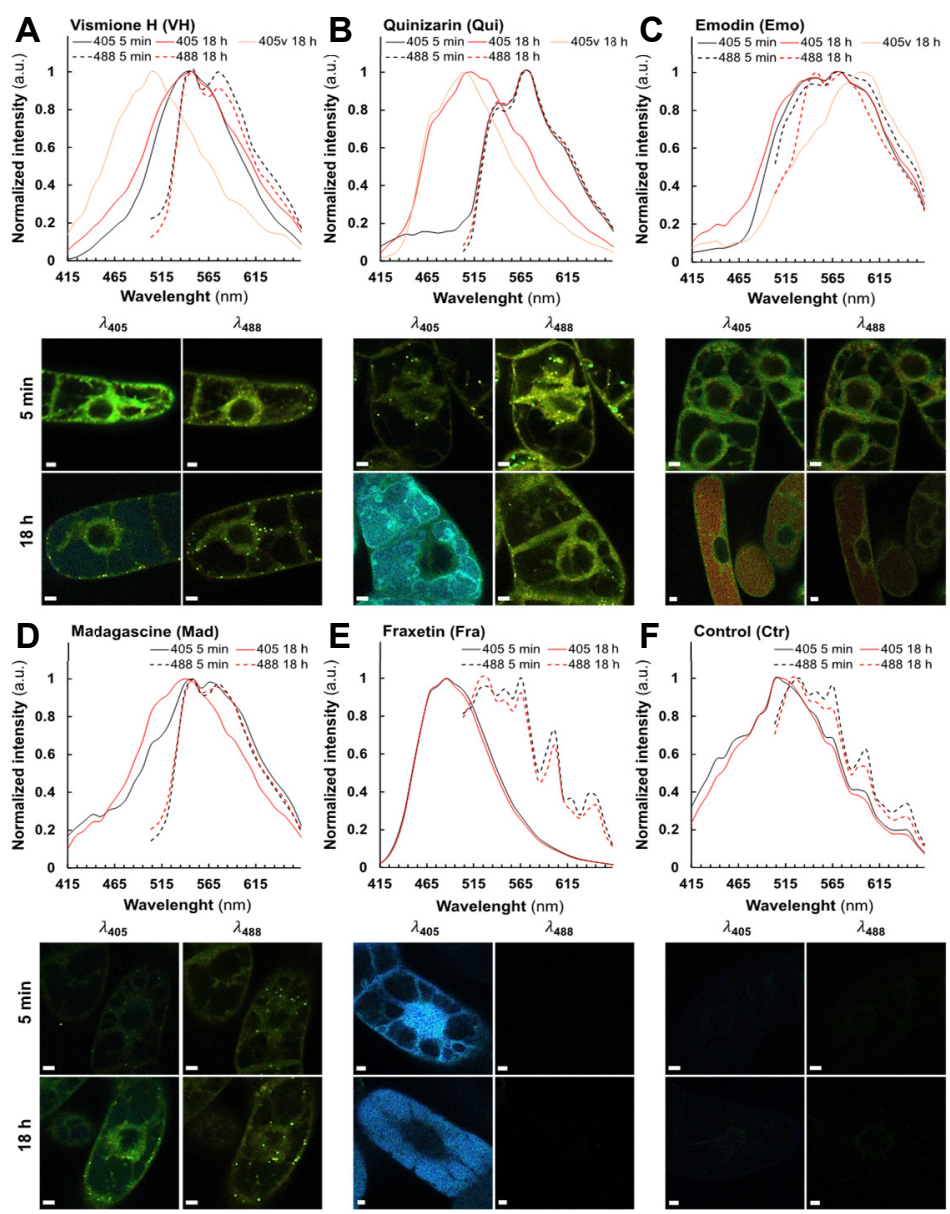

Figure 4. Fluorescence spectra and images of BY-2 cells treated by $25 \mu \mathrm{M}$ of phenolic compounds prior to observation using SImaging. Normalized fluorescence average spectra and lambda view images from SImaging analysis at $\lambda_{405}$ (solid line) and $\lambda_{488}$ (dashed line) of BY- 2 cells treated for $5 \mathrm{~min}$ and $18 \mathrm{~h}$ with $25 \mu \mathrm{M}$ of (A) vismione $\mathrm{H},(\mathbf{B})$ quinizarin, (C) emodin, (D) madagascine, (E) fraxetin, and (F) the negative control without treatment. Spectra observed after 5 min (black), after $18 \mathrm{~h}$ (red) and in the vacuole after $18 \mathrm{~h}$ (red light). Spectra observed in the primary vacuole at $\lambda_{405}$ after $18 \mathrm{~h}$ are specified with a " $\mathrm{v}$ " after the labels if another fluorescence was observed in the cytoplasm. Bars $=20 \mu \mathrm{m}$.

In particular for anthranoids, it was found that their localization and emission spectra did not change significantly over time. Nevertheless, at $\lambda_{405}$, the shape of the emission spectrum in Mad-treated cells was found to be closely related to that of VH (Figure 4A,D). Other treatments have also been associated either with the appearance of a new fluorescence emission signal in the primary vacuole (Figure 4A-C and Figure S10A-C), or to the translocation of an identical fluorescence signal from the nucleus into the primary vacuole as seen in Fra-treated cells (Figure 4E and Figure S10E). These results were further validated by a PCA analysis of the normalized average spectra (Figure 5C,D, Figures S11C,D and S13C,D), giving rise to clustering of fluorescence spectra according to putative structural similarities between the tested molecules in BY-2 cells. For instance, at $\lambda_{488}$ (Figure 5D), the normalized average spectra of anthranoid-treated cells clustered, indicating that anthraquinones fluorescence was observed in contrast to Ctr, Lap, and Fra, which do not fluoresce under these conditions. In addition, normalized average spectra collected at $\lambda_{405}$ (Figure $5 \mathrm{C}$ ) and at $\lambda_{488}$ (Figure 5D) within the cytoplasm, ER and vesicular bodies in VH, and Mad-treated cells were found to be similar and even closer after $18 \mathrm{~h}$ (Figure 5C,D) than after $5 \mathrm{~min}$ (Figure 5A,B). Therefore, they clustered in the PCA analysis. Conversely, the Emo normal- 
ized average spectra are significantly different at $\lambda_{405}$ (Figure $5 \mathrm{C}$ ) and slightly less different at $\lambda_{488}$ (Figure 5D).

Taken together, these results strongly support that VH was transformed in vivo into anthraquinones with a structure closer to that of Mad than to that of Emo. In addition, PCA of standardized average spectra with excitation at $405 \mathrm{~nm}\left(\lambda_{405}\right)$ clearly confirmed the appearance of a new signal observed in the primary vacuole after $18 \mathrm{~h}$ treatment with $\mathrm{VH}-$, Emo-, and Qui-treated cells (Figure 5C), whereas it was not observed using excitation at $488 \mathrm{~nm}\left(\lambda_{488}\right)$.
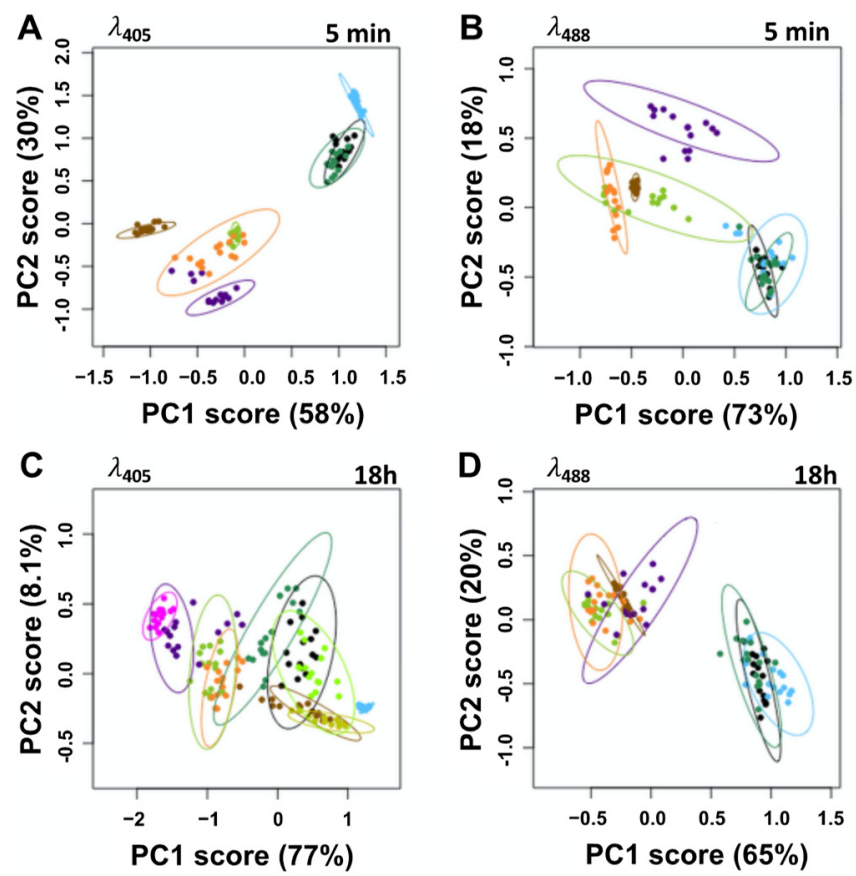

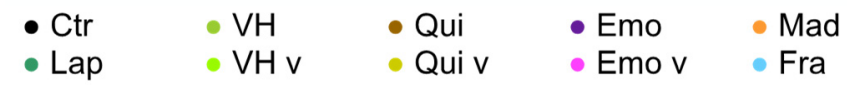

Figure 5. PCA of normalized average spectra obtained by SImaging analysis of BY-2 cells treated or not (Ctr) with $25 \mu \mathrm{M}$ of phenolic compounds. (A,B) Differences observed after 5 min treatments and (C,D) $18 \mathrm{~h}$ with vismione $\mathrm{H}$ VH, madagascine Mad, emodin Emo, quinizarin Qui, fraxetin Fra, and lapachol Lap. Spectra observed at $\lambda_{405}(\mathbf{A}, \mathbf{C})$ and $\lambda_{488}(\mathbf{B}, \mathbf{D})$ in control and treated cells. Spectra found in the primary vacuole at $\lambda_{405}$ after $18 \mathrm{~h}$ are specified with a "v" after the labels if another fluorescence was observed in the cytoplasm. Ellipses are representative of qualitative differences with a $p \leq 0.05$ for the PCA analysis of normalized average spectra.

The fluorescence detected in the primary vacuole is similar to that detected in the cytoplasm for Emo and Qui unlike VH, for which the fluorescence observed in the primary vacuole is significantly different from that measured in the cytoplasm, ER and vesicular bodies. As a partial conclusion, SImaging analyses allowed us to accurately track the fluorescence of $\mathrm{VH}$, related anthranoids and the coumarin (i.e., fraxetin Fra) compared to Lap which exhibits no fluorescence in living cells. Moreover, the new fluorescence spectra observed after $5 \mathrm{~min}$ and $18 \mathrm{~h}$ supports the hypothesis that $\mathrm{VH}$ is metabolized into Mad anthraquinone-types in vivo. Interestingly, we detected signals at $\lambda_{405}$ located in cell compartments whose acidity is below $\mathrm{p} K_{\mathrm{a} 1}$ values in Fra- and VH-treated cells (i.e., $\mathrm{p} K_{\mathrm{a} 1}=8.5$ for Fra and $\mathrm{pK}_{\mathrm{a} 1}=7.2$ for $\mathrm{VH}$ ). According to fluorescence of Fra and $\mathrm{VH}$ in model solution (Table 1), only complexes and especially LBSA species emit strong fluorescence at neutral $\mathrm{pH}$. Thus, the bright signal observed at $\lambda_{405}$ after feeding with $\mathrm{VH}$ and Fra strongly support that part of Fra and VH are complexed in cellula and/or metabolized into related fluorescent compounds. 


\subsection{Fra and Methyl-Fra Derivatives Prevail to Fra-Glycosylated Forms}

An increase in the polarity of given compounds typically results from their oxidation by oxygenases or glycosylation by glycosyltransferases. This metabolization enables then the sequestration of phenolic compounds into the primary cellular vacuole as described with Fra [22,37]. To identify metabolites of Fra, Qui, Emo, Mad, and VH characterized by the fluorescence spectra detected by SImaging, non-targeted metabolomics of methanolic extracts from treated and non-treated BY-2 cells was carried out using UPLC-HRMS/MS. The results were compared to a database including the reference compounds and related metabolites deduced from in silico biotransformation. In this regard, 54 metabolites absent in the control extracts were annotated according to $\mathrm{m} / \mathrm{z}$ of the parent ion and isotopic profile as compared to references or putative catabolites. In addition, hypothetical isomers and/or conjugates were annotated according to MS/MS fragments. As it cannot be excluded that after separation a loss of conjugates occurred in the MS source, the metabolites with different retention times $\left(R_{t}\right)$ but similar $m / z$ and MS/MS fragments were annotated as derivatives represented by putative isomers and/or conjugates.

All references except Lap (Figure S18D and Table S2) were identified in corresponding methanolic extracts of BY-2 cells treated for 15 min or 18 h (Figure 6 and Figure S18A-C and Tables S3-S5). The coumarin mixture annotated in the methanolic extracts from Fratreated cells (Figure 6A) consists of 12 tri-oxygenated forms distributed in Fra and its supposed isomers (F1-F3), six methylated (F4-F9) and three glycosylated forms (F14-F16). The remaining metabolites correspond to tetra-oxygenated coumarins including reduced sideretin and two derivatives (F10-F12) together with another methoxylated form (F13). After $15 \mathrm{~min}$, Fra quickly forms the more polar F2 derivative. Simultaneously, both compounds may have been methylated (F8, F9) or glycosylated (F15, F16).

After $18 \mathrm{~h}$, Fra methylated forms F8 and F9 were significantly reduced in contrast to F2 derivative and F15 or F16 glycosylated forms, remaining constant (Figure 6A). In addition, the Fra derivative F1 abundance was increased 7-fold after $18 \mathrm{~h}$, and other new methylated (F4, F5), hydroxylated (F10), as well as glycosylated (F14) forms were 6 to 33- fold more abundant (Figure 6A and Figure S18A). Thus, the annotated metabolites are consistent with those reported for BY-2 cells treated for 60 min with $20 \mu \mathrm{M}$ of Fra [22]. Although the absolute quantitation was not performed, the Fra isomers or conjugates appeared to be a prevalent form for storage in the primary vacuole, while abundance of glycosylated derivatives did not significantly change over time. In comparison, Lefèvre et al. [22] reported that 7 days-old BY-2 cells treated with Fra $(20 \mu \mathrm{M})$ accumulate $63 \%$ of glycosylated derivatives. The metabolomics and SImaging results suggest that the spectral fingerprint observed at $\lambda_{405}$ after $5 \mathrm{~min}$ and $18 \mathrm{~h}$ Fra treatments corresponds to a mixture of more polar Fra related metabolites rather than Fra itself. In this respect, Fra is metabolized and translocated from the cytoplasm and the nucleus to the primary vacuole for storage/sequestration in BY-2 cells (Figures 4E and 6A,D). However, it was noticed that each group is mostly represented by a metabolite with an intermediate $\mathrm{R}_{\mathrm{t}}(\mathrm{F} 2, \mathrm{~F} 6, \mathrm{~F} 11$, F15) (Figure 6A, Table S3). Although BY-2 cells tend to produce other forms with lower $\mathrm{R}_{\mathrm{t}}$ (more polar), it can be speculated that the latter cannot be over accumulated due to putative cytotoxic effects. This is supported by the accumulation of methylated forms after $18 \mathrm{~h}$, the latter being also reported to decrease negative effects of free hydroxyls from 1-hydroxycantin-6-one in Ailanthus altissima [38]. 


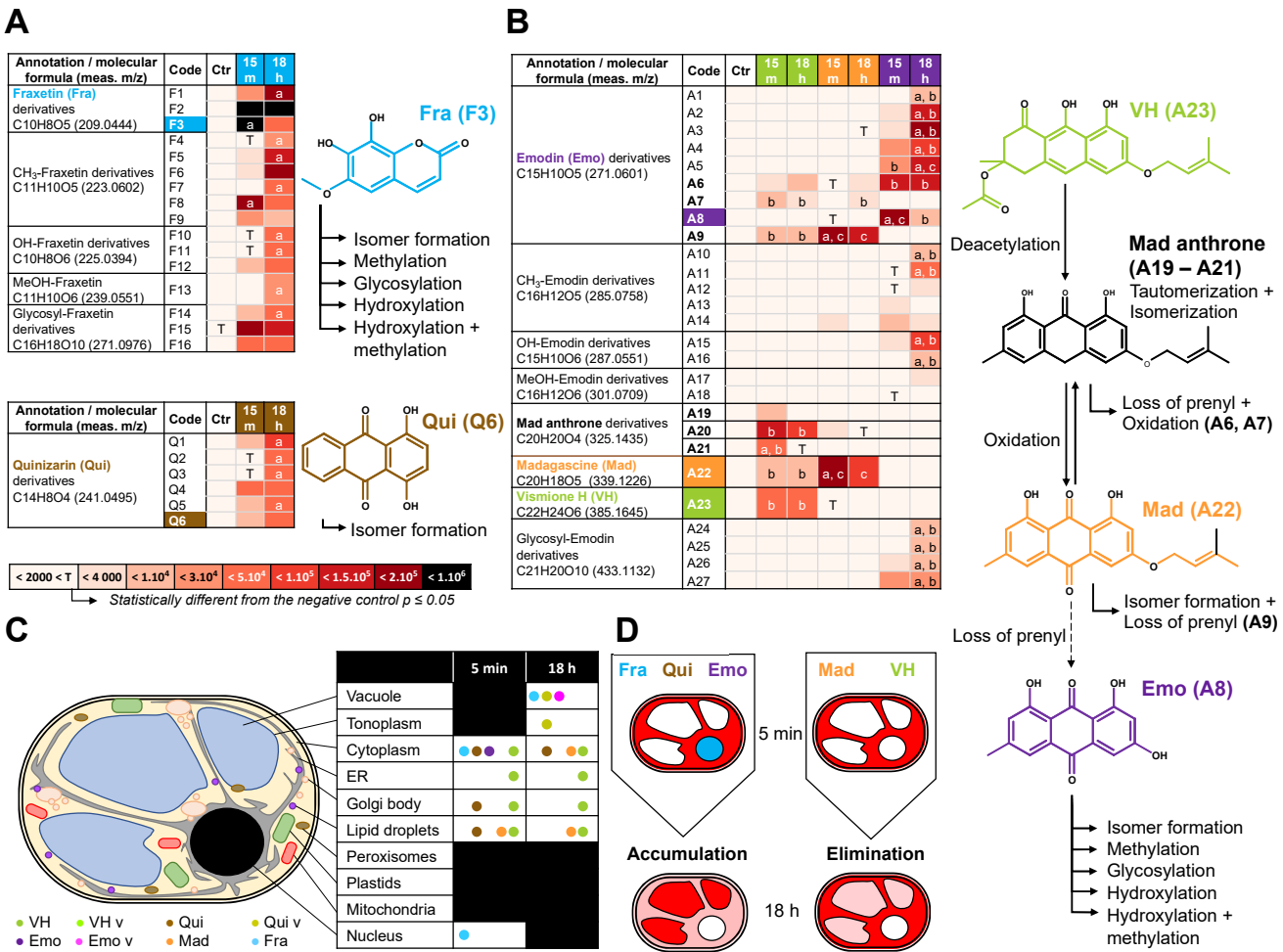

Figure 6. Hypothetical metabolization reactions according to non-targeted analysis of treated BY-2 cells. $m / z$ of parent and daughter ions from references and related metabolites detected by UPLC-HRMS/MS analysis of methanolic extracts from BY-2 cells treated for $15 \mathrm{~min}(15 \mathrm{~m})$ and $18 \mathrm{~h}$ with (A) $50 \mu \mathrm{M}$ of fraxetin Fra (blue), (B) quinizarin Qui (brown), or (C) vismione $\mathrm{H} \mathrm{VH}$ (green), emodin Emo (purple) and madagascine Mad (orange). meas. $m / z=$ measured mass to charge ratio of the most intense adduct detected. Proposed reactions such as hydroxylation $(+\mathrm{OH})$, methylation $\left(+\mathrm{CH}_{3}\right)$, hydroxylation/methylation $(+\mathrm{MeOH})$, glycosylation (+Sugar) and loss of prenyl which may occur in the metabolization processes. The arrows indicate hypothetical reactions according to the references (colored label) and 54 annotations absent or with an area below the significant threshold in negative control samples $(<4000)$. Statistical analysis was performed on area from annotated metabolites $(n=3)$ using Levene with Kruskal-Wallis tests followed by a Dunnett's post-hoc test. Significant differences $(p \leq 0.05)$ between area of metabolites from (a) BY-2 cells treated $15 \mathrm{~min}$ and $18 \mathrm{~h}$ or $(\mathrm{b} \neq \mathrm{c})$ between treatments with anthranoids. (D) Conjuncture of the fluorescence localization in BY-2 subcellular compartments observed by SImaging and the non-targeted metabolomic analysis proposing that Fra, Qui, and Emo derivatives accumulate into the vacuole, while not prenylated anthranoids $\mathrm{VH}$ and Mad being mostly metabolized into other sub-cellular compartments.

\subsection{Metabolization of VH into Anthrones and Anthraquinones}

The metabolomic analyses of extracts isolated from anthranoid treated cells after $15 \mathrm{~min}$ and $18 \mathrm{~h}$ highlighted specificities. For instance, Qui (Q6) and five of its derivatives (Q1-Q5) were found exclusively in Qui-treated cell extracts (Figure 6B, Table S4) while Emo-, Mad-, and VH-treated cells shared a few common metabolites (Figure 6C, Table S5). We noted an absence of methylated, hydroxylated or glycosylated forms, which may be explained by the unusual 4-OH group of Qui found in traces as reported in Cassia obtusifolia extracts [16]. In contrast, most natural anthranoids are found to be hydroxylated at all other positions except the position 2 associated to carboxylic acid progenitors [9]. Accordingly, it can be speculated that Q1-Q5 are five isomers resulting either from a chemical tautomerization/isomerization or from redox processes [11,39]. Meanwhile, it cannot be excluded that $1-\mathrm{OH}$ was removed and the position $\mathrm{C} 5$ or $\mathrm{C} 7$ hydroxylated as reported for Emo $[9,10]$. The specific detection of Qui in related methanolic cell extracts is consistent with its fluorescence detected by SImaging at $\lambda_{488}$. However, the non-targeted metabolomics pointed out that the Qui fluorescence detected in the cytoplasm, lipid droplets and some Golgi bodies may be also related to Q1-Q5 derivatives. In the absence of Q1-Q5 references, we were not able 
to confirm whether these derivatives or Qui contributed to the fluorescence observed and especially that in the primary vacuole $\left(\lambda_{405}\right)$. Thus, it can also be assumed that the latter would have originated from other non-annotated metabolites.

In VH-, Mad-, Emo-treated cells, the Emo (A8) and eight of its derivatives (A1-A7, A9) were detected (Figure 6C, Table S5). In addition, five methylated (A10-A14), two hydroxylated (A15, A16), two methoxylated (A17, A18), and four glycosylated (A24-A27) Emo derivatives were significantly detected only in Emo-treated cells. Surprisingly, Emo and its A1-A6 derivatives were almost exclusive of Emo-treated cells and after $18 \mathrm{~h}$ the A1-A5 abundance significantly increased. In contrast, the Emo derivatives A7 and A9 were specific to Mad and VH-treated cells. This agrees with SImaging and PCA results obtained for Emo-treated cells at $5 \mathrm{~min}$ and $18 \mathrm{~h}$. Indeed, the fluorescence observed mostly in the cytoplasm at $\lambda_{405}$ and $\lambda_{488}$ corresponds to a specific spectral fingerprint of Emo and more likely to A6 content that is unchanged in our metabolomic data at both $15 \mathrm{~min}$ and $18 \mathrm{~h}$. In contrast, it can be proposed that the fluorescence observed in the primary vacuole at $\lambda_{405}$ after $18 \mathrm{~h}$, is from a mixture of the most hydrophilic derivatives (A1-A5), glycosylated (A24, A25) or hydroxylated (A15, A16) forms, being significantly increased after $18 \mathrm{~h}$ as compared to $15 \mathrm{~min}$ (Figure 6C,D). Other metabolites such as VH (A23) as well as Mad anthrone and two putative isomers (A19-A21) were only detected in VH-treated cells, while Mad (A22) was found in VH and Mad-treated cells.

\section{Discussion}

For years, the metabolism, biosynthesis and bioactivity of anthranoids were studied through chemical analysis of metabolites after feeding experiments with radiolabeled precursors [9], genome mining [8,10], and bioassays [5,6], respectively. Our study demonstrates that SImaging is an additional sensitive and suitable tool for the observation of anthranoids in vivo. In depth, unlike classical microscopy, SImaging allowed us to localize and discriminate $\mathrm{VH}$ and related fluorescent metabolites over time, in living cells. Still, UV-Vis spectrophotometric and spectrofluorometric analyses were crucial not only to characterize unbiasedly the fluorescence of compounds in solution, but also to evidence the influence of $\mathrm{pH}$ or complex formation with cations and protein on it. In fact, SImaging had already been used to study the role of coumarins such as scopoline, fraxin and esculin in the iron metabolism of $A$. thaliana roots [40], but not fraxetin Fra (the fraxin genuine). Even though Fra is reported as a non-fluorescent coumarin [21,22], our study evidenced that under alkaline or complexation conditions, its fluorescence is enhanced and modulated depending on the ligand (Table 1). Surprisingly, the Fra fluorescence spectra recorded by SImaging and spectrofluorimetry were significantly different except for Fra-BSA complex (Table 1, Figure 2F, Figure S3B,D). In this context, the overlapping of fluorescence spectra from free and complexed coumarins is limiting for discrimination by SImaging. In fact, extracting spectra to unmix fluorescence signals has been reported (Robe et al., 2021), however our data indicate a cellular colocalization of molecular species that are therefore barely distinguishable even with acquisition settings of the fluorescent signal at $9 \mathrm{~nm} / \mathrm{channel}$. By contrast, the anthranoid fluorescence spectra are consistent between SImaging and spectrofluorimetry analyses, allowing good identification of the fluorescent species observed. The fruitful combination of SImaging with non-targeted metabolomics was particularly effective in identifying at $5 \mathrm{~min}$ and after $18 \mathrm{~h}$, not only key anthranoid metabolites such as madagascine anthrone, Mad and putative emodin derivatives, but also a battery of methylated, hydroxylated, and glycosylated Fra-derivatives. To note, except sideretin, the methylated and hydroxylated Fra-derivatives annotated in our analysis, were not taken into account in the study describing coumarin/iron metabolism in A. thaliana [21,40]. As coumarin accumulation and trafficking is a complex and dynamic process, these derivatives also previously reported in N. tabacum [22], might be considered for further study in A. thaliana as well. Therefore, non-targeted metabolomics shows a clear advantage in elucidating unraveled metabolic pathways and identifying unintended and 
scavenged metabolites prior to targeted metabolomics, being more adapted for systematic quantitation of known metabolites.

For the first time, our study provides an overview of both metabolization processes and subcellular compartments implied in anthranoid metabolism in plants, involving at least five cell compartments after VH treatments (primary vacuole, cytoplasm, ER, Golgi bodies, and lipid droplet vesicular bodies). The cell compartments labelled by anthranoids are consistent with the ER, the cytosol, and the primary vacuole suggested by Han et al. in Rubiaceae [7], and the phenotype observed in melanoma cell culture treated with $10 \mu \mathrm{M}$ Emo or Qui [17]. Collocation experiments with plastids marker was not performed, but in addition to Golgi bodies and lipid droplets, a part of the spherical structures labelled by anthranoids could correspond to plastids as reported in Morinda citrifiolia [41]. Outstandingly, the acetyl vismione D (C3-O-geranyl) was assumed to be not fluorescent enough for observation with fluorescence microscopy [6], here, we characterized the fluorescence in cellula of $\mathrm{VH}$ as well as its degradation products known as madagascine anthrone and anthraquinone. VH is not only converted to Mad anthrone and Mad under oxidative conditions such as in DMSO indeed, but in vivo too. Interestingly, the anthrone A20 remains well detected, whereas in DMSO Mad and bianthrone prevail after $8 \mathrm{~h}$ [6]. After $18 \mathrm{~h}$ the amount of $\mathrm{VH}$, Mad, and A20 remained insignificantly altered in $\mathrm{VH}$ treated cells, while the Mad anthrone derivatives A19, A21 were not detected anymore and Mad abundance considerably decreased in Mad-treated cells after $18 \mathrm{~h}$. Unexpectedly, Mad, which is the less polar molecule $\left(\mathrm{R}_{t}=11.73 \mathrm{~min}\right)$ was metabolized into the A9 derivative rather than Emo (A8), suggesting that in BY-2 cells other reactions occur with Mad prior to loss of the prenyl moiety. In this respect, the bright fluorescence in VH-treated cells observed by SImaging at $\lambda_{405}$ mainly in the cytoplasm (Figure S14C), Golgi bodies (Figure S15), and the ER (Figure S17) corresponds to a mixture of anthranol forms of Mad anthrone and $\mathrm{VH}$ and/or complexes, the anthrones being weakly fluorescent [15]. It can be proposed that $\mathrm{pH}$, intracellular $\mathrm{O}_{2}$, redox levels, or chelation with cations or proteins may stabilize these forms $[15,29,30]$, detected by SImaging in the different subcellular compartments. However, we could not discriminate if the fluorescence observed at $\lambda_{405}$ in the primary vacuole of $\mathrm{VH}$-treated cells after $18 \mathrm{~h}$ corresponded to a non-annotated metabolite or to $\mathrm{VH}-\mathrm{LH}_{2}$ and/or Mad anthrone neutral forms. Since the metabolomic analysis evidenced similar anthraquinones between Mad and VH-treated cell extracts, the spectral fingerprint observed by SImaging at $\lambda_{488}$ corresponds to Mad and likely the specific Emo A9 and/or A7 derivatives.

Taken together, these results point out that $\mathrm{C} 3-\mathrm{OH}$ substitution of anthranoids is a key position influencing both the anthranoid fluorescence and metabolization in BY-2 cells depending on its nature. A free $3-\mathrm{OH}$ allows anthranoid metabolization into very polar Emo derivatives (A1-A6) as well as hydroxylated, methylated, or glycosylated forms dedicated to a vacuolar storage. In contrast when this position is substituted with a prenyl group as for $\mathrm{VH}$ or Mad, the metabolization is markedly altered producing hydrophobic Emo derivatives (A7 and A9). As we were not able to decipher whether enzymatic or chemical reactions contributed to putative oxidation and/or isomerization processes, we can only pinpoint that C3-O-prenylated anthranoid metabolization calls for targeting to lipid droplets, Golgi bodies, and to the ER subcellular location. On a recurring basis, because VH and Mad anthrone were automatically detected in VH reference solution, it can be speculated that both chemical isomerization/tautomerization and VH deacetylation occur in vivo too. However, the remarkable distribution of methylated, hydroxylated, glycosylated, and other derivatives in most treatments is consistent with a well-orchestrated subset of enzymes as it has been described for Fra or Emo [9,21]. To clarify these aspects, in the future it would be interesting to purify fluorescent labelled organellar fractions and analyze the transcriptome and proteome. From a general point of view, the total contents of metabolites detected in Emo and Qui-treated cells were doubled after $18 \mathrm{~h}$, halved for Mad- or VH-treated cells and remained constant in Fra-treated cells (Figure 6D). Although, related metabolites seem to be accumulated over time in Emo, Qui, and Fra-treated cells, 
the abundance of references was $26,3.5$, and 16 times lower after $18 \mathrm{~h}$, confirming their metabolization/storage. In contrast, the Mad and $\mathrm{VH}$ abundance in treated cells changed weakly, supporting the fact that both $\mathrm{VH}$ and Mad are transformed in vivo into nonannotated metabolites and the metabolization rate of prenylated anthranoids in BY-2 cells is limited.

Interestingly, our data unambiguously evidenced that tobacco BY-2 cells are competent to take up and metabolize anthranoids, not produced by N. tabacum plants. Due to its low cost, low autofluorescence, and heterogeneous metabolism, the BY-2 cell model is of particular interest and can undoubtedly be used to study metabolism and localization of other molecules of interest in living organisms. As long as anthranoids and other naturally occurring fluorescent compounds are valuable, it would be interesting to extend this study to investigate the unknown aspects of the biosynthesis pathways and the influence of biotic and abiotic factors on the metabolism of anthranoids and other fluorescent compounds. From another point of view, the developed approach offers interesting perspectives in the medical field, as $\mathrm{VH}$ and similar compounds have been described for their antimalarial properties $[2,5,6]$, but the biological targets as well as mechanisms of action remain unknown. Finally, it would be interesting to reproduce experiments in red blood cells infected by P. falciparum treated with $\mathrm{VH}$ and analogs, therefore opening an avenue to fluorescence localization/structure/activity relationships studies. To be deciphered, the complexity of metabolic pathways requires more than ever multifactorial analyses of living organisms, this SImaging approach coupled with non-targeted metabolomics allows efficient characterization of subcellular location and bioconversion of fluorescent metabolites in living plant cells.

\section{Materials and Methods}

\subsection{Chemicals}

Fraxetin (7,8-dihydroxy-6-methoxy-coumarin), quinizarin (1,4-dihydroxy-anthraquinone), emodin (1,3,8-trihydroxy-6-methyl-9,10-anthracenedione), lapachol (2-hydroxy-3-(3-methyl2-butenyl)-1,4-naphthoquinone) were purchased from Sigma-Aldrich. Vismione $\mathrm{H}$ and madagascine were obtained from PGE2 fraction of Psorospermum glaberimum as previously described [6]. Other chemicals were from the usual commercial sources with the highest purity available.

\subsection{Spectrofluorimetric Analyses}

First, the protonation properties ( $\mathrm{pK}_{\mathrm{a}}$ values) of the selected compounds were measured in a solvent made of $50 \%$ of $\mathrm{EtOH}$ and $50 \%$ water (by volume, Table S1). The latter solvent was used for solubility reasons of the selected compounds. Then, different solutions of the pure compounds at $0.01 \mathrm{mg} / \mathrm{mL}$ were prepared from stock solutions in $\mathrm{EtOH}$ at $1 \mathrm{mg} / \mathrm{mL}$ and then diluted either in $2 \mathrm{~mL}$ of EtOH $/ \mathrm{H}_{2} \mathrm{O} 1: 1 \mathrm{v} / \mathrm{v}, 0.1 \mathrm{M} \mathrm{NaCl}$ adjusted with $\mathrm{HCl} 10^{-2} \mathrm{M}$ (pH 2), $\mathrm{Na}_{2} \mathrm{~B}_{4} \mathrm{O}_{7} 0.01 \mathrm{M}^{\circ} \mathrm{NH}_{4} \mathrm{HCO}_{3}(\mathrm{pH} 10), \mathrm{NaOH} 10^{-2} \mathrm{M}$ (pH 12) or in EtOAc. The absorbance spectra of (de)protonated species in solution were measured from 260-800 nm using a Cary 5000 UV-Vis.-NIR spectrophotometer (Agilent, Santa Clara, CA, USA) prior to any fluorescence analysis. Fluorescence spectra of solutions diluted 10-fold were recorded with $3.5 \mathrm{~mL}$ Suprasil ${ }^{\circledR}$ quartz optical cells of $10 \mathrm{~mm}$ pathlength using a LS-50B spectrofluorimeter monitored with UVWinlab 5.1 software (Perkin Elmer, Waltham, MA, USA). For each compound, the fluorescence emission spectrum was recorded by exciting close to or at the maximum absorption wavelength. The instrumental parameters were adjusted to a scanning speed of $400 \mathrm{~nm} / \mathrm{min}$ and excitation/emission bandwidths adjusted between 4.5 and $15 \mathrm{~nm}$ depending on the conditions. The fluorescence spectra of each compound were established by successive determination of the excitation $\left(\lambda_{\mathrm{Ex}}\right)$ and emission ( $\lambda_{\mathrm{Em}}$ ) maxima. A FluoroMax-4 spectrofluorimeter (HORIBA, Kyoto Japan) was then employed to determine as accurately as possible the quantum yields $\left(\Phi_{\mathrm{F}}\right)$ of anthranoids at $0.001 \mathrm{mg} / \mathrm{mL}$ with the exception of Emo $(0.0015 \mathrm{mg} / \mathrm{mL})$ in solutions at $\mathrm{pH} 2$, then 
at $\mathrm{pH} 10$ only for $\mathrm{VH}$ and Fra. The $\Phi_{\mathrm{F}}$ values of the fluorescent species were calculated by using the equation below with either rhodamine $6 \mathrm{G}(\mathrm{R} 6 \mathrm{G})$ or cresyl violet references.

$$
\Phi_{\mathrm{F}}=\Phi_{\mathrm{R}}\left(\int\left(\mathrm{I}_{\mathrm{F}} \times \mathrm{A}_{\mathrm{R}} \times \mathrm{N}_{\mathrm{F}}^{2}\right) / \int\left(\mathrm{I}_{\mathrm{R}} \times \mathrm{A}_{\mathrm{F}} \times \mathrm{N}_{\mathrm{R}}^{2}\right)\right)
$$

$\Phi_{R}$ corresponds to the quantum yield of reference. The indices $I_{F}$ and $I_{R}$ denote sample and reference, respectively. The integrals over I represent areas of the corrected emission spectra, $A_{R}$ and $A_{F}$ are the optical density at the excitation wavelength for reference and sample, $N_{R}$ and $N_{F}$ correspond to the refractive index of the reference and the sample solutions, respectively.

\section{3. $\mathrm{Ca}^{2+}$ and $\mathrm{Mg}^{2+}$ Chelating Assay}

Fresh stock solution of $\mathrm{VH}(2.6 \mathrm{mM})$ in EtOH was further diluted 100-fold in $2 \mathrm{~mL}$ of EtOH/ $\mathrm{H}_{2} \mathrm{O}$ 1:1 $v / v$ containing $0.1 \mathrm{M} \mathrm{NaCl}$. UV-Vis spectrophotometric titrations of the solutions were then carried out by adding increasing amounts of $\mathrm{CaCl}_{2}$ or $\mathrm{MgCl}_{2}$ and monitored using a Cary 5000 UV-Vis-NIR (Agilent, Santa Clara, MA, USA). Then, $0.1 \mathrm{M} \mathrm{CaCl}_{2}$ or $\mathrm{MgCl}_{2}(25 \mu \mathrm{L})$ prepared in water was successively added to $2 \mathrm{~mL}$ of the ligand solution (VH: $26 \mu \mathrm{M}$ ). The $\mathrm{Ca}^{2+}$ and $\mathrm{Mg}^{2+}$ chelating properties of $\mathrm{VH}$ were also investigated by fluorescence emission, by adding $150 \mu \mathrm{L}$ of $0.1 \mathrm{M} \mathrm{CaCl}_{2}$ or $300 \mu \mathrm{L}$ of $0.1 \mathrm{M}$ $\mathrm{MgCl}_{2}$ solutions to a $2.6 \mu \mathrm{M} \mathrm{VH}$ solution. The $\Phi_{\mathrm{F}}$ values of the $\mathrm{Ca}^{2+}$ and $\mathrm{Mg}^{2+}$ chelates with $\mathrm{VH}$ were measured as described in the spectrofluorimetric analysis section.

\subsection{Plant Material and Treatment}

The Nicotiana tabacum cv. Bright Yellow 2 (tobacco BY-2) cell suspension was made available by Toshiyuki Nagata (Tokyo University, Tokyo, Japan) and cultivated at $26^{\circ} \mathrm{C}$, on a rotary shaker set at $140 \mathrm{rpm}$ in the dark, in modified Murashige and Skoog (MS) medium as reported [42]. For treatments, 7-day old cells were diluted five-fold into fresh MS medium and distributed ( $3 \mathrm{~mL}$ ) in 6-well culture plates (Sarstedt, Nümbrecht Germany) containing 25 or $50 \mu \mathrm{M}$ of VH, Mad, Emo, Qui, Fra or Lap. SImaging acquisitions were carried out either after $5 \mathrm{~min}$ incubation or after $18 \mathrm{~h}$.

\subsection{Spectral Imaging (Simaging) Microscopy}

Treated cells or pure compounds at $1 \mathrm{mM}$ in the solutions at $\mathrm{pH} 2, \mathrm{pH} 10$, and $\mathrm{pH} 12$ were observed using a LSM780 confocal laser microscope (Carl Zeiss, Jena, Germany) equipped with an inverted Zeiss AxioObserver Z1, a Plan-Apochromat 20x/0.8 M27 objective, a numerical zoom adjusted to 2.8 with a laser strength of $5 \%$. Images and emission spectra were acquired using the excitation wavelengths at $405\left(\lambda_{405}\right)$ and $488 \mathrm{~nm}$ $\left(\lambda_{488}\right)$ with the emission light collected into multiple channels incremented by $9 \mathrm{~nm}$ from 415 to $664 \mathrm{~nm}$ and 498 to $664 \mathrm{~nm}$, respectively. The lambda view images correspond to superimposed fluorescence recorded in each channel according to the natural light spectrum. The spectral analysis was performed after the extraction of emission spectra from images by manual component extraction of $1 \mu \mathrm{m}$ circles in different cell compartments labelled by a fluorescence. Images were exported from Zen v2 software (Zeiss, Jena, Germany) and assembled in the figure using ImageJ v1.53d.

\subsection{Spectral Data Analysis}

The dataset consisted of 10 spectra/cell collected from five cells in three independent biological replicates for each treatment, at 25 and $50 \mu \mathrm{M}$, after $5 \mathrm{~min}$ and $18 \mathrm{~h}$. Intensities per channels of each spectrum were averaged per cell and normalized to 1 before statistical analysis with R software V4.0.0 (GNU GPLv2, R Core Team) and RStudio V 1.2.5001 (AGPLv3, RStudio Team (2020). RStudio: Integrated Development for R. RStudio, PBC, Boston, MA, USA http:/ / www.rstudio.com/) using the ChemoSpec package V5.2.12. A distant matrix was established for each dataset applying the Pearson's correlation coefficient, and 
a robust principal component analysis (PCA) was performed. The same procedure was used with solutions of pure compounds to analyze 10 spectra/acquisition in triplicate.

\subsection{Non-Targeted Metabolomic Analysis}

Freeze-dried BY-2 cells (25 mg) treated for 15 min or $18 \mathrm{~h}$ with $50 \mu \mathrm{M}$ of VH, Mad, Emo, Qui, Fra, or Lap were extracted three times in $300 \mu \mathrm{L} \mathrm{MeOH}$, each was sonicated during $20 \mathrm{~min}$ at $80 \mathrm{kHz}$ (FisherbrandTM S-series) and then the extracts were filtered prior to analysis. Standard solution at $0.002 \mathrm{mg} / \mathrm{mL}$ in $\mathrm{EtOH}$ and $\mathrm{MeOH}$ extracts from three independent biological replicates were analyzed by the non-targeted metabolomics approach performed on the UltiMate 3000 UHPLC system (Thermo, Waltham, MA, USA) coupled to the ImpactII (Bruker, Billerica, MA, USA) high resolution Quadrupole Time-ofFlight (QTOF) as previously described [43]. Samples were kept at $4{ }^{\circ} \mathrm{C}, 3 \mu \mathrm{L}$ was injected with a washing step after sample injection with a wash solution $\left(\mathrm{H}_{2} \mathrm{O} / \mathrm{MeOH}, 90 / 10\right.$, $v / v, 150 \mu \mathrm{L}$ ). The spectrometer was equipped with an electrospray ionization (ESI) source and operated in positive ion mode on a mass range from 20 to 1000 Da with a spectra rate of $2 \mathrm{~Hz}$ in AutoMS/MS fragmentation mode. The end plate offset was set at $500 \mathrm{~V}$, capillary voltage at $2500 \mathrm{~V}$, nebulizer at 2 Bar, dry gas at $8 \mathrm{~L}$.min- 1 and dry temperature at $200{ }^{\circ} \mathrm{C}$. The transfer time was set at $20-70 \mu$ and MS/MS collision energy at $80-120 \%$. The MS/MS cycle time was set to $3 \mathrm{~s}$, absolute threshold to $816 \mathrm{cts}$ and active exclusion was used with an exclusion threshold at 3 spectra, release after $1 \mathrm{~min}$ and precursor ion was reconsidered if the ratio current intensity/previous intensity was higher than 5 . Raw data were processed in MetaboScape 4.0 software (Bruker): molecular features were considered and grouped into buckets containing one or several adducts and isotopes from the detected ions with their retention time and MS/MS information when available. The parameters used for bucketing are a minimum intensity threshold of 1000, a minimum peak length of 3 spectra, a signal-to-noise ratio $(\mathrm{S} / \mathrm{N})$ of 3 and a correlation coefficient threshold set at 0.8 . The $[\mathrm{M}+\mathrm{H}]^{+},[\mathrm{M}+\mathrm{Na}]^{+},[\mathrm{M}+\mathrm{K}]^{+}$, and $\left[\mathrm{M}+\mathrm{NH}_{4}\right]^{+}$ions were authorized as possible primary ions. The obtained list of buckets was annotated using a custom analyte list derived from in silico predicted metabolites (catabolites and conjugates) of the compounds of interest. The in silico prediction was performed using MetabolitePredict 2.0 (Bruker) as previously described [44]. Briefly, 79 biotransformation rules were used to predict metabolites over 2 generations. The maximum allowed variation on the mass $(\mathrm{m} / \mathrm{z})$ was set to $3 \mathrm{ppm}$, and the maximum mSigma value (assessing the good fitting of isotopic patterns) was set to 30 . The changes in abundance of each metabolite annotated were determined using statistical analysis by comparing the area obtained under the chromatogram curve of the different metabolites analyzed in triplicates. The homogeneity of the variance was checked with a Levene test prior to a Kruskal-Wallis test, followed by multi comparison procedure using post-hoc Dunnett's test.

Supplementary Materials: The following are available online at https:/ /www.mdpi.com/article/10 .3390/metabo11090571/s1, Figure S1: Influence of $\mathrm{pH}$ on absorption properties of studied phenolic compounds, Figure S2: Fluorescence emission/excitation spectra of studied compounds in solution at different pHs, Figure S3: Normalized fluorescence excitation/emission and absorption spectra of $\mathrm{LNH}_{4}{ }^{+}$and LBSA complexes, Figure S4: UV-Vis. absorption titration of vismione $\mathrm{H}$ by Ca(II), Figure S5: UV-Vis. absorption titration of vismione $\mathrm{H}$ by Mg(II), Figure S6: Absorption and fluorescence emission spectra of anthranoid and fraxetin LBSA complexes, Figure S7: Corrected Absorption and fluorescence properties of fraxetin and vismione LBSA complexes, Figure S8: Images of fluorescent species from studied phenolic compounds in solution observed by SImaging, Figure S9: Normalized average spectra and images from SImaging analysis of lapachol treated cells, Figure S10: Fluorescence spectra and images of BY-2 cells treated with $50 \mu \mathrm{M}$ of phenolic compounds prior to observation using SImaging, Figure S11: Distant matrix of normalized average spectra obtained by SImaging analysis of By-2 cells were treated or not with $25 \mu \mathrm{M}$ of phenolic compounds, Figure S12: PCA of normalized average spectra obtained by SImaging analysis of cells treated or not with $50 \mu \mathrm{M}$ of phenolic compounds, Figure S13: Distant matrix of normalized average spectra obtained by SImaging analysis of cells treated or not with $50 \mu \mathrm{M}$ of phenolic compounds, Figure S14: Anthranoid 
fluorescence locates in the cytoplasm of living BY-2 cells labeled with fluorescein diacetate viability marker after $18 \mathrm{~h}$ of treatment, Figure S15: Vismione $\mathrm{H}$ and related anthraquinone fluorescence locates in the Golgi body of BY-2 cells, Figure S16: Vismione H related anthraquinone fluorescence locates in lipid droplets of living BY-2 cells, Figure S17: Anthranoid fluorescence locates in the endoplasmic reticulum of BY-2 cells, Figure S18: Non-targeted metabolomics of BY-2 cells treated by studied phenolic compounds, Table S1: pKa values of pure compounds measured in solution, Table S2: Metabolites identified in non-targeted metabolomic analysis of MeOH extracts from BY-2 cells treated with $50 \mu \mathrm{M}$ Lap, Table S3: Metabolites identified in non-targeted metabolomic analysis of $\mathrm{MeOH}$ extracts from BY-2 cells treated with $50 \mu \mathrm{M}$ Fra, Table S4: Metabolites identified in nontargeted metabolomic analysis of MeOH extracts from BY-2 cells treated with $50 \mu \mathrm{M}$ Qui, Table S5: Metabolites and fragments identified in non-targeted metabolomic analysis of $\mathrm{MeOH}$ extracts from BY-2 cells treated with $50 \mu \mathrm{M}$ Emo, Mad and VH.

Author Contributions: Conceptualization, Q.C., C.V.-S., A.H., M.E., J.M. and N.G.; Investigation, Q.C., V.M. and M.E.; Resources, Q.C., J.-B.G., N.W., M.E., V.M., C.V., J.M. and C.V.-S.; data curation, Q.C., V.M., M.E., C.V. and M.M.E.; Software Q.C. and M.M.E.; writing-original draft preparation, Q.C., M.E., H.S. and A.H. writing-review and editing, Q.C., J.-B.G., V.M., C.V., M.M.E., M.E., H.S., A.H. and C.V.-S. All authors have read and agreed to the published version of the manuscript.

Funding: This work was supported by the Centre National de la Recherche Scientifique (CNRS) and the University of Strasbourg by core recurrent funding. This research received no external funding. Q.C. wishes to acknowledge the Ministère de l'Enseignement Supérieur, de la Recherche et de l'Innovation (MESRI) for his thesis scholarship (2017-2020) and the University of Strasbourg for a research allowance (ATER, 2020-2021).

Institutional Review Board Statement: Not applicable.

Informed Consent Statement: Not applicable.

Data Availability Statement: The data presented in this study are openly available in FigShare at doi:10.6084/m9.figshare.16540122.

Acknowledgments: We thank Gilles Ulrich (Institut de Chimie des Procédés pour l'Énergie, l'Environnement et la Santé, Strasbourg) for access to the spectrofluorometer to establish reference spectra and quantum yields. We thank to Thomas J. Bach (Institut de Biologie Moléculaire des Plantes, Strasbourg) for sharing the collection of phenolic compounds and to Dimitri Heintz for access to mass spectrometry equipment (metabolomics facility, IBMP). We are also grateful to Stephanie Riché and Sridevi Ramanoudjame (Laboratoire d'Innovation Thérapeutique, Strasbourg) for excellent technical assistance to purify vismione $\mathrm{H}$. We acknowledge helpful criticism and discussion with Romain Duval and Elisabeth Davioud-Charvet.

Conflicts of Interest: The authors declare no conflict of interest.

\section{References}

1. Tissier, A.; Ziegler, J.; Vogt, T. Specialized Plant Metabolites: Diversity and Biosynthesis. In Ecological Biochemistry; Krauss, G.-J., Nies, D.H., Eds.; Wiley-VCH Verlag GmbH \& Co. KGaA: Weinheim, Germany, 2014; pp. 14-37, ISBN 978-3-527-68606-3.

2. Mazimba, O.; Nana, F.; Singh, G.S. Xanthones and Anthranoids from the Medicinal Plants of Africa. In Medicinal Plant Research in Africa; Kuete, V., Ed.; Elsevier: Amsterdam, The Netherlands, 2013; pp. 393-434, ISBN 978-0-12-405927-6.

3. Dong, X.; Fu, J.; Yin, X.; Cao, S.; Li, X.; Lin, L.; Huyiligeqi Ni, J. Emodin: A Review of Its Pharmacology, Toxicity and Pharmacokinetics: Emodin: Pharmacology, Toxicity and Pharmacokinetics. Phytother. Res. 2016, 30, 1207-1218. [CrossRef]

4. Srinivas, G.; Babykutty, S.; Sathiadevan, P.P.; Srinivas, P. Molecular mechanism of emodin action: Transition from laxative ingredient to an antitumor agent. Med. Res. Rev. 2007, 27, 591-608. [CrossRef] [PubMed]

5. François, G.; Steenackers, T.; Assi, L.A.; Steglich, W.; Lamottke, K.; Holenz, J.; Bringmann, G. Vismione H and structurally related anthranoid compounds of natural and synthetic origin as promising drugs against the human malaria parasite Plasmodium falciparum: Structure-activity relationships. Parasitol. Res. 1999, 85, 582-588. [CrossRef] [PubMed]

6. Gallé, J.-B. Pharmacochimie d'anthranoïdes Issus Du Genre Psorospermum (Hypericaceae): Isolement, Activités Antipara-sitaires et Synthèse d'analogues Structuraux Jean-Baptiste Galle. Ph.D. Thesis, Université de Strasbourg, Strasbourg, France, 2015.

7. Han, Y.-S.; Van Der Heijden, R.; Verpoorte, R. Biosynthesis of anthraquinones in cell cultures of the Rubiaceae. Plant Cell, Tissue Organ Cult. 2001, 67, 201-220. [CrossRef]

8. Kang, S.-H.; Pandey, R.P.; Lee, C.-M.; Sim, J.-S.; Jeong, J.-T.; Choi, B.-S.; Jung, M.; Ginzburg, D.; Zhao, K.; Won, S.Y.; et al. Genome-enabled discovery of anthraquinone biosynthesis in Senna tora. Nat. Commun. 2020, 11, 5875. [CrossRef]

9. Gill, M. The Biosynthesis of Pigments in Basidiomycetes. Aust. J. Chem. 2001, 54, 721. [CrossRef] 
10. Chiang, Y.-M.; Szewczyk, E.; Davidson, A.D.; Entwistle, R.; Keller, N.P.; Wang, C.C.C.; Oakley, B.R. Characterization of the Aspergillus nidulans Monodictyphenone Gene Cluster. Appl. Environ. Microbiol. 2010, 76, 2067-2074. [CrossRef]

11. Fain, V.Y.; Zaitsev, B.E.; Ryabov, M.A. Tautomerism of anthraquinones: V. 1,5-Dihydroxy-9,10-anthraquinone and its substituted derivatives. Russ. J. Org. Chem. 2006, 42, 1662-1667. [CrossRef]

12. Furumoto, T.; Jindai, A. Isolation and Photoisomerization of a New Anthraquinone from Hairy Root Cultures ofSesamum indicum. Biosci. Biotechnol. Biochem. 2008, 72, 2788-2790. [CrossRef]

13. Elkazaz, S.; Jones, P.B. Photochemical Hydroxylation of 1-Methyl-9,10-anthraquinones: Synthesis of 9'-Hydroxyaloesaponarin II. J. Org. Chem. 2010, 75, 412-416. [CrossRef]

14. Duval, R.; Duplais, C. Fluorescent natural products as probes and tracers in biology. Nat. Prod. Rep. 2017, 34, 161-193. [CrossRef]

15. Fujii, T.; Mishima, S.; Tanaka, N.; Kawauchi, O.; Kodaira, K.; Nishikiori, H.; Kawai, Y. Absorption and fluorescence spectra of 9-anthrol and its chemical species in solution. Res. Chem. Intermed. 1997, 23, 829-839. [CrossRef]

16. Rossi, S.; Tabolacci, C.; Lentini, A.; Provenzano, B.; Carlomosti, F.; Frezzotti, S.; Beninati, S. Anthraquinones danthron and quinizarin exert antiproliferative and antimetastatic activity on murine B16-F10 melanoma cells. Anticancer Res. 2010, 30, 445-449.

17. Verebova, V.; Belej, D.; Joniova, J.; Jurasekova, Z.; Miskovsky, P.; Kozar, T.; Horvath, D.; Stanicova, J.; Huntosova, V. Deeper insights into the drug defense of glioma cells against hydrophobic molecules. Int. J. Pharm. 2016, 503, 56-67. [CrossRef]

18. Conéjéro, G.; Noirot, M.; Talamond, P.; Verdeil, J.-L. Spectral analysis combined with advanced linear unmixing allows for histolocalization of phenolics in leaves of coffee trees. Front. Plant Sci. 2014, 5, 39. [CrossRef]

19. Talamond, P.; Verdeil, J.-L.; Conéjéro, G. Secondary Metabolite Localization by Autofluorescence in Living Plant Cells. Molecules 2015, 20, 5024-5037. [CrossRef]

20. Nagata, T.; Nemoto, Y.; Hasezawa, S. Tobacco BY-2 Cell Line as the "HeLa" Cell in the Cell Biology of Higher Plants. In In-ternational Review of Cytology; Elsevier: Amsterdam, The Netherlands, 1992; Volume 132, pp. 1-30, ISBN 978-0-12-364532-6.

21. Tsai, H.-H.; Rodríguez-Celma, J.; Lan, P.; Wu, Y.-C.; Vélez-Bermúdez, I.C.; Schmidt, W. Scopoletin 8-Hydroxylase-Mediated Fraxetin Production Is Crucial for Iron Mobilization. Plant Physiol. 2018, 177, 194-207. [CrossRef] [PubMed]

22. Lefèvre, F.; Fourmeau, J.; Pottier, M.; Baijot, A.; Cornet, T.; Abadia, J.; Álvarez-Fernández, A.; Boutry, M. The Nicotiana tabacum ABC transporter NtPDR3 secretes O-methylated coumarins in response to iron deficiency. J. Exp. Bot. 2018, 69, $4419-4431$. [CrossRef]

23. Binzel, M.L.; Hess, F.D.; Bressan, R.A.; Hasegawa, P.M. Intracellular Compartmentation of Ions in Salt Adapted Tobacco Cells. Plant Physiol. 1988, 86, 607-614. [CrossRef]

24. Carden, D.E.; Walker, D.J.; Flowers, T.J.; Miller, A.J. Single-Cell Measurements of the Contributions of Cytosolic Na+ and K+ to Salt Tolerance. Plant Physiol. 2003, 131, 676-683. [CrossRef]

25. Shen, J.; Zeng, Y.; Zhuang, X.; Sun, L.; Yao, X.; Pimpl, P.; Jiang, L. Organelle pH in the Arabidopsis Endomembrane System. Mol. Plant 2013, 6, 1419-1437. [CrossRef]

26. Martinière, A.; Bassil, E.; Jublanc, E.; Alcon, C.; Reguera, M.; Sentenac, H.; Blumwald, E.; Paris, N. In Vivo Intracellular pH Measurements in Tobacco and Arabidopsis Reveal an Unexpected pH Gradient in the Endomembrane System. Plant Cell 2013, 25, 4028-4043. [CrossRef]

27. Friedman, M.; Jürgens, H.S. Effect of pH on the Stability of Plant Phenolic Compounds. J. Agric. Food Chem. 2000, 48, 2101-2110. [CrossRef]

28. Giusti, M.M.; Wrolstad, R.E. Characterization and Measurement of Anthocyanins by UV-Visible Spectroscopy. Curr. Protoc. Food Anal. Chem. 2001, 1, F1.2.1-F1.2.13. [CrossRef]

29. Hlasiwetz, H.; Grabowski, A. Mittheilungen aus dem chemischen Laboratorium in Innsbruck. I. Ueber die Carminsäure. Ann. Chem. Pharm. 1867, 141, 329-345. [CrossRef]

30. Cameron, D.; Edmonds, J.; Raverty, W. Oxidation of emodin anthrone and stereochemistry of emodin bianthrone. Ann. Chem. Pharm. 1976, 29, 1535-1548. [CrossRef]

31. Sedaira, H.; Idriss, K.A.; Seleim, M.M.; Abdel-Aziz, M.S. Use of Quinizarin as a Spectrophotometric Reagent for MgO Content Analysis of Portland Cement and Cement Clinker. Monatshefte Für Chem. Chem. Mon. 1998, 129, 49-58. [CrossRef]

32. Hepler, P.K. Calcium: A Central Regulator of Plant Growth and Development. Plant Cell 2005, 17, 2142-2155. [CrossRef]

33. Waters, B.M. Moving magnesium in plant cells: Commentary. New Phytol. 2011, 190, 510-513. [CrossRef]

34. Guo, W.; Chen, S.; Hussain, N.; Cong, Y.; Liang, Z.; Chen, K. Magnesium stress signaling in plant: Just a beginning. Plant Signal. Behav. 2015, 10, e992287. [CrossRef]

35. Duval, R.; Cottet, K.; Blaud, M.; Merckx, A.; Houzé, S.; Grellier, P.; Lallemand, M.-C.; Michel, S. A Photoalkylative Fluorogenic Probe of Guttiferone A for Live Cell Imaging and Proteome Labeling in Plasmodium falciparum. Molecules 2020, 25, 5139. [CrossRef] [PubMed]

36. Dudev, T.; Lim, C. Monodentate versus Bidentate Carboxylate Binding in Magnesium and Calcium Proteins: What Are the Basic Principles? J. Phys. Chem. B 2004, 108, 4546-4557. [CrossRef]

37. Stringlis, I.A.; De Jonge, R.; Pieterse, C.M.J. The Age of Coumarins in Plant-Microbe Interactions. Plant Cell Physiol. 2019, 60, 1405-1419. [CrossRef]

38. Osoba, O.A.; Roberts, M.F. Methyltransferase activity in Ailanthus Altissima cell suspension cultures. Plant Cell Rep. 1994, 13, 277-281. [CrossRef] [PubMed] 
39. Batchelor-McAuley, C.; Dimov, I.B.; Aldous, L.; Compton, R.G. The electrochemistry of quinizarin revealed through its mediated reduction of oxygen. Proc. Natl. Acad. Sci. USA 2011, 108, 19891-19895. [CrossRef] [PubMed]

40. Robe, K.; Conejero, G.; Gao, F.; Lefebvre-Legendre, L.; Sylvestre-Gonon, E.; Rofidal, V.; Hem, S.; Rouhier, N.; Barberon, M.; Hecker, A.; et al. Coumarin accumulation and trafficking in Arabidopsis thaliana: A complex and dynamic process. New Phytol. 2021, 229, 2062-2079. [CrossRef]

41. Yamamoto, H.; Tabata, M.; Leistner, E. Cytological changes associated with induction of anthraquinone synthesis in photoautotrophic cell suspension cultures of Morinda lucida. Plant Cell Rep. 1987, 6, 187-190. [CrossRef]

42. Hemmerlin, A.; Bach, T.J. Farnesol-Induced Cell Death and Stimulation of 3-Hydroxy-3-Methylglutaryl-Coenzyme A Reduc-tase Activity in Tobacco Cv Bright Yellow-2 Cells. Plant Physiol. 2000, 123, 1257-1268. [CrossRef]

43. Villette, C.; Zumsteg, J.; Schaller, H.; Heintz, D. Non-targeted metabolic profiling of BW312 Hordeum vulgare semi dwarf mutant using UHPLC coupled to QTOF high resolution mass spectrometry. Sci. Rep. 2018, 8, 13178. [CrossRef]

44. Villette, C.; Maurer, L.; Wanko, A.; Heintz, D. Xenobiotics metabolization in Salix alba leaves uncovered by mass spectrometry imaging. Metabolomics 2019, 15, 122. [CrossRef] 